Review

\title{
Probiotics, Prebiotics and Immunomodulation of Gut Mucosal Defences: Homeostasis and Immunopathology
}

\author{
Holly Hardy, Jennifer Harris, Eleanor Lyon, Jane Beal and Andrew D. Foey *
}

School of Biomedical \& Biological Sciences, University of Plymouth, Drake Circus, Plymouth PL4 8AA, UK; E-Mails: holly.hardy@plymouth.ac.uk (H.H.); jennifer.harris@plymouth.ac.uk (J.H.); eleanor.lyon@plymouth.ac.uk (E.L.); jane.beal@plymouth.ac.uk (J.B.)

* Author to whom correspondence should be addressed; E-Mail: andrew.foey@plymouth.ac.uk; Tel.: +44-1752-584623.

Received: 5 March 2013; in revised form: 8 May 2013 / Accepted: 9 May 2013 /

Published: 29 May 2013

\begin{abstract}
Probiotics are beneficial microbes that confer a realistic health benefit on the host, which in combination with prebiotics, (indigestible dietary fibre/carbohydrate), also confer a health benefit on the host via products resulting from anaerobic fermentation. There is a growing body of evidence documenting the immune-modulatory ability of probiotic bacteria, it is therefore reasonable to suggest that this is potentiated via a combination of prebiotics and probiotics as a symbiotic mix. The need for probiotic formulations has been appreciated for the health benefits in "topping up your good bacteria" or indeed in an attempt to normalise the dysbiotic microbiota associated with immunopathology. This review will focus on the immunomodulatory role of probiotics and prebiotics on the cells, molecules and immune responses in the gut mucosae, from epithelial barrier to priming of adaptive responses by antigen presenting cells: immune fate decision-tolerance or activation? Modulation of normal homeostatic mechanisms, coupled with findings from probiotic and prebiotic delivery in pathological studies, will highlight the role for these xenobiotics in dysbiosis associated with immunopathology in the context of inflammatory bowel disease, colorectal cancer and hypersensitivity.
\end{abstract}

Keywords: probiotics; prebiotics; synbiotics; immunomodulation; tolerance; activation; cytokines; inflammatory bowel disease; cancer; hypersensitivity 


\section{Introduction}

The regular intake of beneficial microorganisms, or probiotics, is an extensively-studied approach for tapping into the health benefits bestowed by commensal microorganisms colonising the gastrointestinal tract (GIT) of the healthy human host. The probiotic strains used for human consumption must be of human origin, non-pathogenic and survive gastrointestinal transit in order to confer health benefits on the host [1]. Owing to their non-pathogenic profile Lactobacilli and bifidobacteria are the most commonly used species and significantly influence human health through a range of effects which include; detoxification of xenobiotics [2], biosynthesis of vitamin $\mathrm{K}$ [3], metabolic effects of fermentation of indigestible dietary fibre [4], positive influence on transit of luminal contents by peristalsis [5], competition with pathogenic microbes for nutrients and binding sites on mucosal epithelial cells [6] and modulation of the host's immune response [7].

Non-pathogenic bacteria such as probiotic strains of Escherichia coli have been demonstrated to exclude pathogens by suppressing pathogenic growth through the secretion of potent antimicrobial peptides (AMPs) such as the bacteriocin, microsin S [8]. Moreover, co-administration with prebiotics (synbiotics) may work in cooperation to selectively promote the growth and activity of one or more beneficial probiotic species [9,10]. Ingestion of prebiotics alone can stimulate the activity of pre-existing indigenous species which have the potential to be a more cost-effective strategy in positively modifying pre-exisiting commensal microflora $[11,12]$. Prebiotics are defined as natural or processed 'functional foods' which contain biologically active compounds that have documented clinical benefits on health, ranging from prevention of colorectal cancer to modulation of host defences to viral and bacterial infections by altering the interactions between pathogenic and beneficial bacteria $[9,13]$. The most extensively studied prebiotics are the fructans (inulin, fructo-oligosacharides (FOS)) and galacto-oligosaccharides (GOS) which, owing to their chemical structure, are indigestable in the small intestine and are anaerobically fermented by bacteria in the colon $[14,15]$. This fermentation of non-digestible dietary fibre/carbohydrate results in the production of short chain fatty acids, (SCFAs - acetate, proprionate, butyrate), that have significant positive impacts on intestinal epithelial cell function, including maintenance of metabolism, proliferation, differentiation and promotion a low $\mathrm{pH} 5$ of the gut environment, favouring beneficial microbes with a concomitant reduction in pathogen bacterial growth and viability [16,17].

\section{Commensalism}

The human body plays host to communities of beneficial microorganisms whose collective numbers exceed that of human host's somatic and germ cells [18]. The microbial inhabitants, referred to as the microbiota, mediate key physiological processes in exchange for nutrients and a sheltered habitat in which they are able to reproduce. Strong host selection lead to their co-evolution, whereby indigenous microbes increased host fitness by encouraging cooperation; promoting stable functionality of the gut ecosystem [19]. Metagenomics has revealed the depth of this mutualistic relationship, allowing characterisation of the microbial flora from particular locations of the GIT, regardless of whether the bacteria can be cultured in the laboratory [20]. Although these microbes reside along the length of the gastrointestinal tract, 16s ribosomal sequencing of samples from the colon has identified that the 
Firmicutes and the Bacteroidetes are the two dominant phylogenetic types [21]. The human gut microbiome consists of a huge diversity and density of commensal bacteria, which display numerical and strain variation according to anatomical location along the GIT. This species variation is dependent on local environmental conditions and substrate/nutrient availability. Generally, in healthy human hosts, the stomach contains a low density of commensal bacteria with species of Lactobacillus, Streptococcus and Helicobacter pylori predominanting. Bacterial density increases with transit down the GIT, where densities of $10^{3}$ to $10^{6} \mathrm{cfu} / \mathrm{mL}$ are found in the small intestine which facilitate the growth and survival of Streptococcus and Lactobacillus and finally, Bacteroides, Clostridium, Fusobacterium and Bifidobacterium reside in the large intestine/distal gut at densities of $10^{8}$ to $10^{9}$ [21]. Thus, due to this strain and density variation of commensal bacteria along the GIT, the consequences to competition with pathogens for binding sites and nutrients, anti-microbial peptide production and even modulation of the host's immune responsiveness will dramatically vary from one location to another in the gut. Furthermore, these beneficial stable microbiomes, found in the healthy host, are subject to dramatic changes in their resident populations as a consequence of pathological mechanisms: patients with inflammatory bowel disease (IBD) either Crohn's disease (CD) or ulcerative colitis (UC) exhibit reduced microbial diversity in conjunction with disproportionate quantities of gram-negative bacteria when compared to healthy subjects [22].

Exposure to microbes in early life begins with the colonisation of the newborn intestine. Infants born by conventional delivery are colonised at first by vaginal and faecal bacteria of the mother, whereas those born by caesarean section (CS) are initially exposed to bacteria originating from the hospital environment [23,24]. In a study of 165 births, CS infants had lower bacterial counts at one month of age along with significantly decreased populations of bifidobacteria compared to their conventionally born counterparts. Although these differences were no longer apparent at the age of 6 months, CS infants were shown to have greater levels of IgA-, IgG-, and IgM-secreting cells, compared to their conventionally born counterparts, up until the study was completed at 1 year of age [25]. This evidence suggested that lower numbers of initial colonising bacteria, in particular bifidobacteria, may impede establishment of a stable gut microflora during a critical period of immune education and development. This would result in altered collective composition with a lasting influence on immune function far beyond infancy, modifying clearance efficiency of infections and propagation of aberrant immune responses [25].

Diet is another important contributing factor to development of the core microbiome during early life. Human milk is a complex biological fluid which supplies fats, proteins, carbohydrates and minerals for the growing infant [26]. In addition to satisfying nutritional requirements, colostrum and milk have been shown to provide early immune education and passive immunity through the synergistic action of many bioactive molecules and cells, including immunoglobulins, lysozyme, lactoferrin [26] as well as being a continuous source of commensals such as L. acidophilus, L. gasseri [27], B. bifidium, and B. breve [28]; the compostition of which is mirrored in the infant during the period of breastfeeding [29]. Fernandez et al., proposed that, in addition to bacteria being transferred from mother to infant from the breast skin microbiota, there may be a dendritic cell- or macrophage-mediated trafficking of bacteria from the maternal gut epithelium to the mammary gland epithelium [30]. Moreover, human milk also contains a mix of oligosaccharides which do not nourish the infant but are instead fermented by colonic microbiota in the infant [31]. Human milk 
oligosaccharides (HMOs) have been shown to selectively promote the growth and activity of bifidobacteria in vitro demonstrating prebiotic-like properties [32-34]. The exact impact of breastfeeding on the building of the core gut microbiome of the infant is confounded by contemporary practices other than caesarean delivery, including the use of antibiotics and supplementation of nursing with formula milk $[35,36]$.

The generation of germ-free (GF) mice has been an essential tool for assessing the impact of composition of the microbiota on the immune system as well as eluding to how particular imbalances can be detrimental to human health. For example, the absence of microbial stimulation in GF animals leads to deficits in lymphoid structures such as the spleen [37] and Peyer's patches [38] as well as abnormal numbers of immune cell types [39] and expression of cytokine profiles [40]. Specific combinations of species have been shown to drive development of the gut associated lymphoid tissue (GALT) such as B. fragilis and B. subtilis, thought to enhance microfold cell transcytosis. In particular, protein YqxM (stress response controlled by Spo0A in sporulation of B. subtilis) is suggested to play a critical role, although a mutant strain (unable to sporulate but can secrete protein YqxM) was unable to initiate development. Either, B. subtilis must be around long enough to induce GALT development or additional sporulation-specific factors are also required [41].

The effects of imbalances in gut microflora are not restricted to the gastrointestinal tract and may have an impact on systemic immunity, culminating in allergic disorders such as asthma and atopy [42], and autoimmune disease such as type 1 diabetes [43] and multiple sclerosis [44]. Specific pathogen free (SPF) mice have been shown to have poorly defined splenic tissue architecture and a lower proportion of $\mathrm{CD}^{+}$T-cells compared to conventional mice, with no difference in $\mathrm{CD} 8^{+} \mathrm{T}$-cells and $\mathrm{CD}_{19}{ }^{+}$B-cells, an effect attributed to polysaccharide A associated with B. fragalis [7]. Such observations further support the 'hygiene hypothesis' which proposes that a lack of immune challenges, result in the inadequate maturation of the immune system and predispose individuals to food allergy, asthma [45], IBD, type 1 diabetes and multiple sclerosis [46].

It can be concluded that the establishment and maintenance of a stable gut microbiome, through the appropriate exposure to commensal organisms and their prebiotic substrates as a consequence of birth, breast-feeding, weaning and feeding/infectious challenge, has an important impact on colonisation population dynamics and hence, the well-being of the host. Experimental studies have indicated the importance of these commensal organisms in the development of immune tissues, immune education and protection to immunological insults; dysregulation of these commensal populations resulting in immunopathology. To document the roles played by commensal and probiotic organisms in the host's immune system, it is imperative to first focus on the site of initial introduction and colonisation, the mucosal epithelial barrier of the gut.

\section{The Mucosal Epithelial Barrier of the GIT}

The mucosal epithelia of the gut provide an enormous surface area for invading pathogens to gain access to the internal environment of the body. The very characteristics that make the mucosa excellent at physiological activities, such as absorption, also confer vulnerability to pathogenic invasion and infection. The integrity of this barrier can be enhanced by probiotics in a number of ways. Probiotic strains, such as lactobacilli and bifidobacteria, compete for adhesive access to attachment sites on 
epithelial cells, such as those provided by mannose specific interactions [47], as well as for nutrients which prevents colonisation by pathogenic bacteria [48,49] (Refer to Figure 1).

Figure 1. Probiotic and prebiotic modulation of intestinal barrier and immune responses.

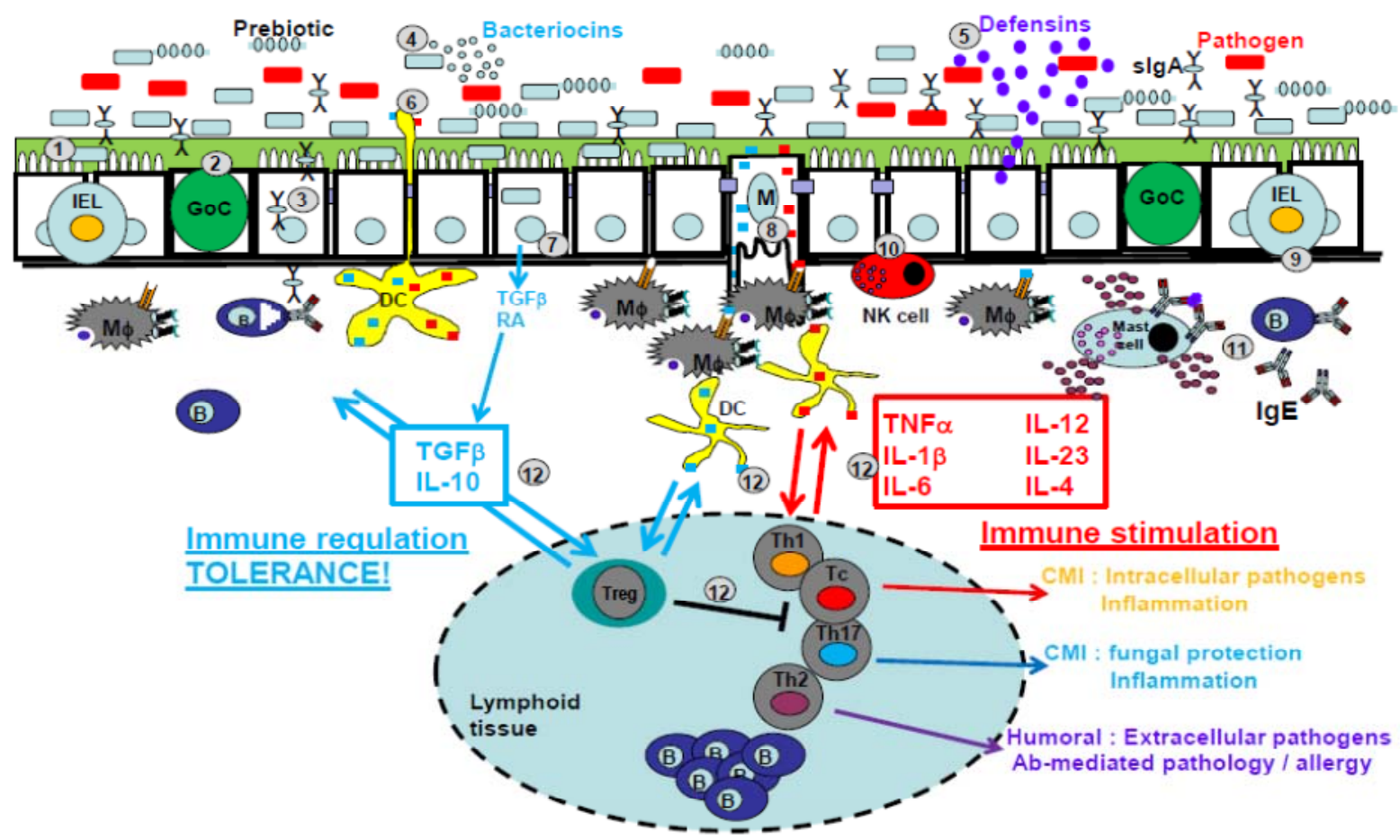

Prebiotics and probiotics exert a range of effects on mucosal barrier function and the responses of the underlying immune tissue of the GALT. Probiotic and commensal microbes (light blue rectangles), assisted by prebiotics (light blue strings), out-compete pathogenic organisms (red rectangles) for nutrients and binding sites on the epithelial cell surface (1). This barrier function is enforced by the ability of probiotics to influence mucin expression and mucus secretion from the goblet cells $(\mathrm{GoC}, 2)$ and by pathogen neutralisation by $\operatorname{IgA}$ in the mucus layer, facilitated by pIgR-mediated transcytosis of $\operatorname{sg} \mathrm{A}$ through the epithelial cell (3). Probiotic bacteria can induce anti-microbial peptides against pathogens either directly, as bacteriocins (4) or activation of epithelial cells to secrete defensins (5). Luminal gut contents are tasted by three mechanisms: directly via DCs extending dendrites through the tight junction and into the lumen (6), epithelial cell pinocytosis of microbiota (7) or by selective transfer of luminal contents via specialised epithelial cells, microfold (M) cells (8). Interspersed between epithelial cells, intraepithelial lymphocytes (IELs - predominantly CD8+) contribute to the cytotoxic, killing response of the epithelial barrier (9). The innate killing response can be activated in NK cells via APC production of IL-12 and the production of IL-15 by epithelial cells (10). Immunity to extracellular parasites is elicited through B cell class switching to IgE production and the sensitisation of mast cells/granulocytes, which upon secondary exposure, release primary amines such as histamine (type I hypersensitivity) (11). Finally, the adaptive response elicited is dependent of the presentation responses of $6,7 \& 8$. If these APCs present safe commensal/probiotic (blue) peptides, then tolerogenic mechanisms driven by TGF $\beta$, IL-10 and retinoic acid are initated-resulting in suppression of T effector responses (Th1, Th2, Th17, Tc) and IgA production. If APCs present pathogenic peptides (red), then the default setting of tolerance is bypassed and as a result of the immune stimulatory cytokine environment, effector responses are initiated: Th1-CMI to intracellular pathogens, Th17-CMI to fungal infection and Th2-humoral responses to extracellular pathogens (12). Probiotics modulate this on/off switch of the mucosal immune system in a strain-dependant manner. Inappropriate modulation by probiotics or pathogenic subversion of mucosal immunity can result in immunopathology: allergy, inflammatory bowel disease and cancer. 


\subsection{Intestinal Epithelial Cells}

Barrier integrity is strengthened by commensals and probiotics. Enterocytes express epithelial growth factor receptor (EGF-R), which when activated induces enhancement of the epithelial barrier and tight junctions, probiotic strains have been found to promote this response [50]. Probiotic bacterial cell wall products such as peptidoglycan have been shown to augment apical tightening and sealing of tight junctions by activation of the pattern recognition receptor, TLR-2 [51]. In addition, as yet uncharacterised soluble factors, secreted into conditioned media by Lactobacillus rhamnosus GG, have been shown to up-regulate the expression of heat shock protein (hsp) 25 and hsp72 in intestinal epithelial cells in vitro [52,53], conferring protection against a variety of cellular stresses including oxidative stress-mediated apoptosis [54,55].

\subsection{Mucus}

Integral to gut barrier defence is mucus, composed of mucins. Mucins are a family of heavy molecular weight proteins that display extensive glycosylation and are constitutively secreted by goblet cells interspersed throughout the intestinal epithelium [56]. Mucin polymerisation provides the structural foundation of the mucus, granting protection from pathogens, enzymes, toxins, dehydration and abrasion [57]. Lactobacillus plantarum 299v and Lactobacillus rhamnosus GG have been shown to up-regulate production of MUC2 and MUC3 intestinal mucins which subvert the adherence of the enteropathogenic bacterium Escherichia coli $\mathrm{O} 157: \mathrm{H} 7$ to intestinal epithelial cells, consequently preventing pathogenic bacterial translocation [58]. It is thought that this probiotic-mediated modulation of mucin expression is a strategy for intestinal colonisation of beneficial microbes to the host [59]. Furthermore, mucins may exert prebiotic-type effects as carbohydrate content can account for $90 \%$ of their weight [60]. Molecular cloning of glycoside hydrolases from Bifidobacterium bifidum have been shown to specifically catalyse oligosaccharides that exist within mucins which can be used as an energy source $[61,62]$.

\section{3. $\operatorname{Ig} A$}

Protease-resistant $\operatorname{IgA}$ is integral to barrier function, playing an important role in trapping pathogens/pathogenic material (neutralisation) in the mucus layer through its ability to bind mucins [63]. Probiotic strains such as Lactobacillus GG, Bifidobacterium lactis Bb-12 [64] and Saccharomyces boulardii [65] have been demonstrated to enhance IgA production and secretion through alteration of the cytokine milieu in the gut mucosa. Probiotic bacteria have been shown to induce epithelial cell expression of TGF $\beta$ and IL-10 as well as IL-6 which potentiate IgA production through B-cell maturation and class-switching in favour of $\operatorname{IgA}[66,67]$. Finally, probiotics can induce/augment the expression of polymeric Ig receptors on the basolateral surface of intestinal epithelial cells enhancing transcytosis of IgA through the epithelial cell and into the glycocalyx/gut lumen [68]. 


\subsection{Antimicrobial Peptides}

Also important to barrier defence against pathogenic microbes is the ability of epithelial cells, probiotics and commensals to produce antimicrobial peptides (AMPs). Bacteriocins are antimicrobial peptides produced by the majority of bacterial organisms that are thought to contribute to probiotic functionality by assisting with colonisation [69,70], direct elimination of pathogens [71] and acting as signalling molecules directing other bacteria or the host immune system [72]. Many studies have shown that production of bacteriocins by microbiota can lead to sustained presence of beneficial bacterial strains in the GIT. A study using a Lactobacillus strain mix demonstrated an improved clinical outcome of pigs infected with Salmonella, attributable to the production of bacteriocins by Lactobacillus salivarius [73]. This is supported by a study using Pediococcus acidilactici probiotic which reduced the viability of Listeria monocytogenes [74]; an effect unobservable in vivo. The anti-microbial peptide lacticin also failed to protect against infection from Listeria monocytogenes [33], highlighting a possible variance in bacteriocin efficiency in vivo. In the case of C. difficile infection, a targeted approach using Bacillus thuringiensis which produces the narrow-spectrum bacteriocin, thuricin $\mathrm{CD}$, is highly effective at killing $C$. difficile whilst having no significant impact on the microbiota composition [75]. In contrast however, broadspectrum bacteriocins such as lacticin 3147 produced by Lactococcus lactis subsp. lactis DPC3147 has been shown to negatively impact on members of the Firmicutes and Bacteroidetes [76].

Defensins are a family of highly conserved small cysteine-rich AMPs particularly abundant at mucosal sites where they contribute to the host defence by disrupting the cytoplasmic membrane of susceptible microorganisms [77,78]. Paneth cells, residing within the epithelium at the bottom of intestinal crypts, secrete defensin-rich granules upon exposure to bacterial products such as LPS, LTA and muramyl dipeptide [79]. A study using healthy human subjects demonstrated that probitotic Escherichia coli Nissle 1917 was able to induce human beta-defensin (hBD)-2 [80], mediated by flagellin-dependent NF-kappaB- and AP-1 pathways [81]. In addition, probiotic Lactobacilli strains are not only able to up-regulate enterocyte hBD-2 production in vitro [82]; some species, such as Lactobacillus lactis, have been demonstrated to be resistant to the anti-microbial effects of this defensin [83]. Furthermore, as well as their role as AMPs, hBD1 and hBD2 have been reported to play a more direct role in modulating host immunity, acting as chemoattractants for $\mathrm{T}$ cells and immature dendritic cells through binding CCR6 [84].

\subsection{Intraepithelial Lymphocytes}

Invasive enteropathogenic bacteria such as E. coli, Salmonella typhimurium or Clostridium difficile can cause intracellular infection of host cells. Located within the epithelium are intraepithelial lymphocytes (IELs) these are a diverse group of cells, predominantly consisting of $\mathrm{CD} 8^{+} \mathrm{T}$ cells, sub-divided by their differential TCR expression; either the $\gamma \delta$ - or $\alpha \beta$-TCR. Intraepithelial $\gamma \delta$ cells have been shown to respond to affected enterocytes within hours of infection by secreting the antibacterial lectin, RegIII $\gamma$, or directly lysing cells using a natural killer-like effector killing mechanism. These $\gamma \delta$ IELs express the receptor NKG2D which responds to host cells displaying signs of infection and cellular stress [85,86]. Interestingly, a recent study using the TNBS-experimentally 
induced colitis model demonstrated that treatment with a mix of L. acidophilus and B. longum probiotics suppressed inflammatory destruction of the gut which was associated with the influx of $\gamma \delta^{+}$ IELs, increased $\mathrm{CD}^{+}$Treg populations and IL-10 within the area and a corresponding down-regulation in $\mathrm{CD}^{+} \mathrm{T}$ effector cells and pro-inflammatory cytokines [87].

The Aryl hydrocarbon receptor (AhR) is heavily expressed by IELs, ligation of which is necessary in maintaining IELs within the gut mucosa, preventing their migration away from this site to elsewhere in the system. The ligand for the receptor is found in cruciferous vegetables, and it has been shown that a reduction in AhR expression leads to increased bacterial load in the gut and increased tendency towards colitis [88]. Ligation of the AhR receptor is a mechanism for Treg induction, and has been used experimentally to supress Th2 mediated allergy to peanuts via induction of $\mathrm{CD} 4{ }^{+} \mathrm{CD} 25^{+} \mathrm{Foxp} 3^{+}$ Tregs [89]. Within the mucosa the AhR signalling pathway was triggered experimentally by L. plantarum a common probiotic found in food, and observed to promote inhibitors of the NF- $\mathrm{B}$ pathway which suggested that this probiotic induces tolerance to food antigens [90].

It is thus becoming apparent that the commensal/probiotic, mucus/glycocalyx and epithelial cell barriers are not just physical and chemical barriers to pathogenic infection, but represent a clear communication system resulting in direct modulation of host-driven immune responses.

\section{Immunomodulatory Role of Probiotic Bacteria}

The gut mucosal epithelium not only acts as a barrier to unwanted pathogenic organisms but represents a mechanism of safely and selectively tasting luminal contents of the gut, passing this information underneath the barrier to the immune cells/tissue of the GALT in the lamina propria and beyond in the mesenteric lymph nodes. This selective tasting of the contents of the GIT is the way in which the host tolerates that which is beneficial non-self (through the mechanism of immune tolerance/hyporesponsiveness) and mounts protective immune responses to that which is pathogenic non-self (through humoral and cell-mediated immune mechanisms). The process by which this antigenic information is passed to the underlying cells is crucial to this immune fate: tolerance/suppression versus activation. There are generally three mechanisms in which antigenic material is processed and presented to the underlying immune cells and that these mechanisms are controlled by three different types of antigen-presenting cells (APCs) (refer to Figure 1).

\subsection{Tasting of Luminal Contents}

These three main cell types, which communicate information about the microflora and the digesta to underlying immune cells are epithelial cells, specialised epithelial cells called microfold (M) cells and dendritic cells (DCs). Epithelial cells or enterocytes, at the apical surface, are linked by tight junctions preventing the penetration of microbial pathogens; these cells however, can facilitate vesicular bacterial/antigenic transfer across the barrier by receptor-mediated pinocytosis. Once inside the cell, antigenic material can be processed and presented in the context of a major histocompatibility complex molecule (MHC) expressed with co-stimulatory molecules on the basolateral membrane, thereby activating lymphocytes located beneath in the lamina propria [91,92]. Although enterocytes/ epithelial cells are antigen presenting cells (APCs); in the presence of inflammation, it has been shown that under normal circumstances they fail to express the co-stimulatory molecules (CD80 or CD86) 
required for activation of lymphocytes. Thus, they function to induce anergy in $\mathrm{CD}^{+} \mathrm{T}$ cells and therefore induce a tolerant environment in the presence of commensals [93].

Gut mucosal DCs represent the second mechanism of sampling luminal contents and priming immune activation or tolerisation. In a safe environment of commensal organisms and beneficial dietary components, immune activation is suppressed by TGF- $\beta$ and TSLP, secreted by epithelial cells in response to commensal bacteria, hence promoting a default non-inflammatory humoral environment $[94,95]$. Ligation of TLRs on the apical surface of enterocytes has been linked to DC activation which, via a fractalkine receptor $\mathrm{CX}_{3} \mathrm{CR} 1$-dependant mechanism, project arm-like extensions (dendrites) between the tight junctions of the epithelial barrier allowing them to independently sample the luminal contents [96,97]. Upon sampling, DCs become influential APCs, having phagocytosed antigen they can migrate to mesenteric lymph nodes where they stimulate lymphocyte proliferation, or they can activate localised lymphocytic cells. This mechanism is important for the sampling of luminal contents without reducing transepithelial resistance/barrier integrity [98].

The third cell type which enables the cross talk between the microbiota and the host's immune system is the microfold (M) cell, located within the epithelial monolayer above areas of follicular lymphoid tissue referred to as Peyer's Patches. Here M cells form a gateway, transcytosing microbes and allowing controlled access to a range of immune cell types, inducing expansion and activation of follicular lymphocytes [99]. Unlike enterocytes they do not secrete anti-microbial components or present antigen, but instead shuttle macromolecules and microorganisms to other effector cells such as DCs and macrophages present in the $\mathrm{M}$ cell pocket. However, certain pathogens have evolved to recognise $\mathrm{M}$ cells as the entry point into the host's tissue, thus evading detection by other epithelial surveillance mechanisms [100].

\subsection{Recognition of Pathogenic and Commensal Bacteria}

Recognition of luminal bacteria as either commensal or pathogenic is of great importance to the mucosal immune system in eliciting positive immune activatory- or negative, tolerising-responses. Innate pathogen recognition receptors (PRRs) such as Toll-like receptors (TLRs) respond to pathogen associated molecular patterns (PAMPs) and are expressed by enterocytes and mucosal APCs (DCs and macrophages). The binding of PAMPs to these innate receptors triggers intracellular signalling cascades, resulting in the release of specific cytokines, exerting anti-viral, pro- or anti-inflammatory effects on neighbouring cells. The expression of TLRs is down-regulated on the apical membrane of the epithelial barrier in comparison to the basolateral side; TLR2 and TLR4 are expressed at low levels on the apical surface and drive tolerance to LPS and peptidoglycan, expressed in the cell walls of commensal bacteria [101]. Equally, basolateral activation of TLR5 by flagellin, a common component of pathogenic bacteria, leads to a heightened pro-inflammatory response, resulting from the translocation of pathogenic flagellin across the epithelium. No such translocation, hence pro-inflammatory response, was observed for commensal E. coli flagellin [102]. Indeed, healthy, homeostatic colonic epithelial cells were observed to be unresponsive to bacterial flagellin whereas flagellin that had gained entry to the basolateral surface elicited a TLR5-dependant inflammatory response [103]. This provides a defensive strategy against virulent pathogens, which gain entry by 
circumnavigating the antigen processing and presentation pathways. Indeed, exposure to virulent pathogenic bacteria induces epithelial cell secretion of IL-8, a chemokine initiating the recruitment and infiltration of neutrophils and commencement of inflammation [104]. The ingestion of the probiotic culture VSL\#3 however, has been linked to a dampening down of this response, reducing IL-8 secretion even in the presence of pathogenic Salmonella dublin [105].

A large proportion of the indigenous bacteria are Gram-negative which accounts for a high LPS load. Intestinal alkaline phosphatase can be expressed by epithelial cells under the control of LPS, originating from normal microbiota [106]. This enzyme is thought to cleave glutamine and phosphate from LPS moieties [107], leaving a dephosphorylated LPS that is unable to activate TLR4 signalling; effectively suppressing proinflammatory responses such as neutrophil activation [108]. Importantly, the localisation of intestinal alkaline phosphatase is largely confined to the apical surface [109]; allowing modification of luminal LPS whilst allowing an immune response to be initiated upon successful bacterial invasion and breaching of the epithelial barrier. This is indicative of a fine balance of bacterial PAMP recognition that descriminates between activation and tolerisation. Indeed, in addition to positive activatory immune mechanisms, recognition of bacterial PAMPs can exhibit inhibitory mechanisms. These mechanisms include a range of strategies to suppress TLR-mediated activatory signals including; (i) reduction in TLR expression, (ii) expression of shed/secreted receptors (sTLR2, sTLR4, sCD14, sST2), (iii) expression of decoy receptors (SIGIRR, ST2L, RP105) and (iv) expression of endogenous inhibitors of TLR signalling pathways (Myd88s, Tollip, A20, IRAK-M, SARM, TRAIL-R, ATF-3, TRIAD3A and possibly NOD2). These strategies have been described to be employed by a range of cells including IECs and monocyte/macrophage lineage cells that are vital to gut mucosal immune functionality (reviewed in [110]).

\subsection{Lumenal Contents Determine Immune Fate: Tolerance or Activation?}

These processing and presentation pathways mediated by epithelial cells, DCs and M cells are pivotal to immune fate decisions upon tasting the gut luminal contents. In the context of safe non-self or harmful non-self (utilising TLRs), these cells pass on the antigenic information resulting in immune regulation/tolerance or immune activation. In safe, homeostatic environments, antigenic sampling results in mucosal tolerance that is dominated by regulatory $\mathrm{T}$ cells (Tregs). CD4 ${ }^{+}$Tregs are key to the negative regulatory component of immune responsiveness, acting to suppress unnecessary inflammation and the differentiation of effector cells, such as T-helper (Th) cells and cytotoxic T-cells (Tc). In comparison to other T-cell subsets, Tregs express increased levels of CD25 (IL-2R $\alpha$ ) and the endogenous co-stimulatory inhibitor, CTLA-4, with the majority of CD4 ${ }^{+} \mathrm{CD} 25^{+}$Tregs expressing the Treg marker, Foxp3. The presence of Foxp3 is essential for Treg differentiation, leading to the production and secretion of anti-inflammatory/regulatory cytokines, such as IL-10 and TGF- $\beta$, which mediate Treg suppressive effects $[111,112]$. In pathologies whereby negative signalling is defective, the therapeutic reinstatement of a tolerogenic setting, through up-regulation of regulatory mediators or the down-regulation of pro-inflammatory mediators, can result in the resolution of chronically inflamed tissue. One characteristic feature of some probiotics is the ability to suppress pro-inflammatory responses through the up-regulation of tolerogenic mechanisms. 
A number of mouse model experiments conducted to observe the effects of probiotic administration have identified a ubiquitous characteristic in both Lactobacillus and Bifidobacterium strains. Lavasani et al., using mice with developing encephalomyelitis, identified that $L$. paracasei and L. plantarum induced $\mathrm{CD}^{+} \mathrm{CD} 25^{+}$Foxp $^{+}$T-regs in mesenteric lymph nodes leading to increased TGF- $\beta$ levels and reduced inflammation in the CNS [113]. Other studies have confirmed this immunomodulatory effect, with a range of Lactobacillus strains shown to increase TGF- $\beta$ and IL-10 levels [114-116]. Many of the aforementioned studies also found probiotic mediated inhibition of pro-inflammatory cytokines including IFN $\gamma$, IL-6 and TNF $\alpha$, further supporting the role for probiotics in suppression of pro-inflammatory immunity. There is, however, a study which conflicts with these findings, demonstrating the ability of $L$. acidophilus and $L$. salivarius to decrease IL-10 and TGF- $\beta$ levels in the rectum of BALB/c mice. The study further observed no differences in Treg modulation of bystander T-cell function, between control and probiotic-fed mice [117]. The findings of this study, despite being uncharacteristic, may demonstrate anatomical and strain variance in probiotic immunomodulatory function.

To address the mechanisms behind probiotic induced Treg activation, studies have explored the role of probiotics in modulating DC function. L. reuteri and L. casei have been found to prime DCs to produce increased levels of IL-10 and inhibit the proliferation of bystander effector T-cells; an effect found to involve probiotic engagement of the C-type lectin, DC-SIGN [115]. B. breve has also been identified as a mediator of IL-10 production, however unlike the Lactobacillus strains, was found to act through MyD88-dependent TLR-2 signalling in $\mathrm{CD}_{103}{ }^{+}$DCs [116]. Engagement of TLR2 has been shown to result in the rapid release of IL-10, which subsequently inhibits opposing cytokines such as the Th1-polarising cytokine, IL-12 [118] and CD103 ${ }^{+}$DCs are known to induce Foxp3 ${ }^{+}$T-cells in a TGF- $\beta$ and retinoic acid (RA)-dependent manner [119]. Collectively, this suggests mechanisms by which probiotics interact with DC subtypes to induce a tolerogenic setting predominated by anti-inflammatory cytokines, IL-10 and TGF- $\beta$. These studies also highlight Lactobacillus as activators of conventional DCs and Bifidobacterium as activators of $\mathrm{CD} 103^{+} \mathrm{DCs}$, implying strain variance in DC-subset targeting and functionality.

\subsection{Cytokines Are Pivotal to This Immune Cell Fate}

It is well established that immune fate decisions (activation or tolerance) are made by immune cells, which are activated by, and elicit an effector response by specific functionality and profiles of the immune cell signals, cytokines. Environmental cytokines can elicit pro-inflammatory responses (TNF $\alpha$, IL-1 $\beta$, IL-6, IL-8, IL-15) and anti-inflammatory/suppressive responses (IL-10, TGF $\beta$ ), through the direction of a wide array of effector cells which include granulocytes, macrophages, DCs, T \& B cells. In addition, cytokines drive Th1 differentiation (IL-12) hence CMI via IFN $\gamma$, Th2 differentiation (IL-4) and humoral responses via IL4, IL-5, IL-13, IL-10; Th17 differentiation (TGF $\beta$, IL-1 $\beta$, IL-6 \& IL-23) and anti-pathogen responses via IL-17A and IL-22, Treg differentiation (IL-10, TGF $\beta$, IL-35) and suppression via the production of IL-10, TGF $\beta$ and IL-35 (refer to Figure 1). There is a wealth of research literature which documents the ability of probiotics to modulate cytokine production; either via immune activation/augmentation, immune deviation or suppression. Modulation of such cytokine expression will have an appreciable impact on immune functionality and represents a clear avenue of 
manipulation for probiotic use in the treatment and prophylaxis of immunopathology. Many Lactobacillus strains have been described to induce IFN $\gamma$ and IL-12, which are Th1-cytokines associated with CMI and NK activity whereas other Lactobacillus strains both augment and suppress the Th2-associated cytokines, IL-4 and IL-5, which drive humoral immune responses. More recently, Evrard et al. [120], has described L. rhamnosus to induce IL-23, an IL-12 family member associated with Th17 differentiation and pro-inflammatory responses. Additionally, a wide range of both bifidobacteria and Lactobacillus induce expression of the anti-inflammatory/regulatory cytokines, TGF $\beta$ and IL-10, associated with Treg suppressive function/tolerance (for a full citation of probiotic modulation of $\mathrm{T}$ cell differentiation/functionality, refer to Table 1).

Table 1. Probiotic strains differentially modulate T cell differentiation and effector cytokines.

\begin{tabular}{|c|c|c|c|c|}
\hline Cytokines (Immune Response) & Cell system & \begin{tabular}{|l|} 
Response \\
\end{tabular} & Probiotic strain & References \\
\hline \multirow{15}{*}{$\begin{array}{l}\text { IFN- } \gamma \& \text { IL-12 }\left(\text { Th }_{1} \text {-associated, }\right. \\
\text { CMI and NK cell activity) }\end{array}$} & \multirow{10}{*}{ PBMCs } & \multirow{10}{*}{ Increase } & L. rhamnosus & [121] \\
\hline & & & $\begin{array}{l}\text { L. plantarum } \\
\text { L. lactis } \\
\text { L. casei } \\
\text { L. rhamnosus GG }\end{array}$ & [122] \\
\hline & & & L. lactis W58 & [123] \\
\hline & & & L. casei Shirota & [124] \\
\hline & & & L. casei Shirota & [125] \\
\hline & & & $\begin{array}{l}\text { L. paracasei } \\
\text { L. salivarius }\end{array}$ & [126] \\
\hline & & & B. longum W11 & [127] \\
\hline & & & $\begin{array}{l}\text { L. rhamnosus } \\
\text { L. gasseri } \\
\text { B. bifidum } \\
\text { E. coli (TG1) }\end{array}$ & [128] \\
\hline & & & L. casei Shirota & [129] \\
\hline & & & L. plantarum strains & {$[130]$} \\
\hline & PBMC-Mo & Increase & $\begin{array}{l}\text { S. aureus } \\
\text { L. johnsonii }\end{array}$ & [114] \\
\hline & PBMC-DCs & Increase & $\begin{array}{l}\text { L. salivarius } \\
\text { L. rhamnosus Lcr35 }\end{array}$ & $\begin{array}{l}{[131]} \\
{[120]}\end{array}$ \\
\hline & PBMC-NK cells & Increase & $\begin{array}{l}\text { L. acidophilus } \\
\text { L. reuteri }\end{array}$ & [132] \\
\hline & Myeloid DCs & Increase & $\begin{array}{l}\text { L. gasseri } \\
\text { L. johnsonii } \\
\text { L. reuteri }\end{array}$ & [133] \\
\hline & PBMC-NK cells & Decrease & B. bifidum & [132] \\
\hline \multirow{3}{*}{$\begin{array}{l}\text { IL-23 \& IL-17 }\left(\mathrm{Th}_{17} \text {-associated, }\right. \\
\text { pro-inflammatory) }\end{array}$} & Mo-DCs & Increase & L. rhamnosus Lcr35 & {$[120]$} \\
\hline & PBMCs & Decrease & $\begin{array}{l}\text { B. breve } \\
\text { LGG }\end{array}$ & [134] \\
\hline & Caco- 2 cell line & Decrease & L. plantarum & {$[135]$} \\
\hline
\end{tabular}


Table 1. Cont.

\begin{tabular}{|l|l|l|l|l|}
\hline & & & $\begin{array}{l}\text { L. plantarum } \\
\text { L. lactis } \\
\text { L. casei } \\
\text { L. rhamnosus GG }\end{array}$ & {$[122]$} \\
\cline { 3 - 4 } $\begin{array}{l}\text { IL-4 \& IL-5 }\left(\mathrm{Th}_{2} \text {-associated, }\right. \\
\text { humoral })\end{array}$ & \multirow{4}{*}{ PBMCs } & Decrease & {$[123]$} \\
\cline { 3 - 5 } & & $\begin{array}{l}\text { Bifidobacteria } \\
\text { L. rhamnosus } \\
\text { L. gasseri } \\
\text { B. bifidum }\end{array}$ & {$[128]$} \\
\hline \multirow{2}{*}{$\begin{array}{l}\text { TGF- } \beta \text { (Treg-associated, } \\
\text { anti-inflammatory) }\end{array}$} & PBMCs & Increase & B. longum & {$[136]$} \\
\cline { 2 - 5 } & Epithelial cells & Increase & $\begin{array}{l}\text { B. lactis } \\
\text { L. johnsonii }\end{array}$ & {$[137]$} \\
\hline
\end{tabular}

Overview of studies documenting the probiotic strain-specific effects on Th1 cytokines (IFN $\gamma$ and IL-12) associated with cell-mediated immunity, Th17 cytokines (IL-23 and IL-17) associated with pro-inflammatory anti-pathogen responses, Th2 cytokines (IL-4 and IL-5) - humoral immunity and Treg (TGF $\beta$ ) associated with immune tolerisation/suppression. All studies are human studies utilising a range of cell sources: peripheral blood mononuclear cells (PBMCs), NK cells, DCs, monocytes (Mo) and Caco-2 gut epithelial cells.

In addition to differentiating $\mathrm{CD}^{+} \mathrm{T}$ helper cells to distinct lineages responsible for cell mediated immunity and humoral immune responses, probiotics also have an important role in the modulation of innate inflammatory responses important for early, non-specific anti-pathogen responses and a potential role in the regulation of chronic inflammatory responses. A range of both Lactobacillus and Bifidobacterium species augment the secretion of TNF $\alpha$, IL-1 $\beta$ and IL-6 by PBMCs, DCs, monocytes, macrophages and epithelial cells. In contrast there is both a differential and overlapping probiotic strain induction of the anti-inflammatory cytokine, IL-10. Of particular interest is the suppressive effect of L. casei Shirota on PBMC production of IL-10 [129], an effect which may be explained by the documented effect of LcS on the induction of the Th1-polarising cytokine, IL-12. (For a full citation of probiotic modulation of inflammatory cytokines, refer to Table 2).

Finally, one of the greatest producers of cytokine is the tissue macrophage. These cells are present in large numbers in the lamina propria of the GIT and, as such, play an important role in driving immune responsiveness in the gut. These mucosal macrophages exhibit a degree of functional plasticity which is determined by the local tissue environment. As such, macrophages can exist as M1-like pro-inflammatory and M2-like anti-inflammatory/regulatory subsets (reviewed in [138]). Recently, probiotic strains have been described to differentially regulate macrophage cytokine production in a strain- and subset-specific manner [139,140]. The inflammatory response being dictated by both the probiotic strain and which macrophage subset is being activated, hence macrophage populations can display differing inflammatory outcomes as a consequence of which subset is predominant in the tissue environment being challenged. Of relevance to prebiotic research, the SCFA, butyrate, produced as a consequence of anaerobic fermentation of prebiotic non-digestible carbohydrates, has also been demonstrated to play a role in macrophage cytokine production; again, the inflammatory cytokine outcome being determined by macrophage subset [141]. Thus, cytokines determine immune responsiveness to commensals, pathogens or in the case of dysregulation, immunopathology. 
Table 2. Probiotic strains differentially modulate pro- and anti-inflammatory cytokines.

\begin{tabular}{|c|c|c|c|c|}
\hline Cytokines (Immune Response) & Cell system & Response & Probiotic strain & References \\
\hline \multirow{10}{*}{$\begin{array}{l}\text { TNF- } \alpha \text { and IL- } 1 \beta \\
\text { (Pro-inflammatory) }\end{array}$} & \multirow{5}{*}{ PBMCs } & \multirow{5}{*}{ Increase } & $\begin{array}{l}\text { L. rhamnosus } \\
\text { L. bulgaricus } \\
\text { S. pyogenes } \\
\end{array}$ & {$[121]$} \\
\hline & & & Bifidobacteria & {$[142]$} \\
\hline & & & L. casei Shirota & $\begin{array}{l}{[124]} \\
{[129]}\end{array}$ \\
\hline & & & \begin{tabular}{|l|} 
L. salivarius \\
L. fermentum
\end{tabular} & {$[143]$} \\
\hline & & & L. plantarum strains & {$[130]$} \\
\hline & PBMC-DCs & Increase & L. rhamnosus Lcr35 & {$[120]$} \\
\hline & Myeloid DCs & Increase & L. reuteri & {$[133]$} \\
\hline & Epithelial cells & Increase & L. sakei & {$[137]$} \\
\hline & \begin{tabular}{|l} 
Macrophage \\
subset cell line
\end{tabular} & $\begin{array}{l}\begin{array}{l}\text { Increase and decrease } \\
\text { (subset-specific) }\end{array} \\
\end{array}$ & L. casei Shirota & $\begin{array}{l}{[139]} \\
{[140]} \\
\end{array}$ \\
\hline & THP-1 cell line & Decrease & L. reuteri & {$[144]$} \\
\hline \multirow{3}{*}{ IL-6 (Pro-inflammatory) } & PBMCs & Increase & $\begin{array}{l}\text { L.rhamnosus } \\
\text { L. bulgaricus } \\
\text { S. pyogenes } \\
\end{array}$ & {$[121]$} \\
\hline & Epithelial cells & Increase & $\begin{array}{l}\text { B. lactis Bb12 } \\
\text { L. casei CRL431 } \\
\text { L. helveticus R389 }\end{array}$ & $\begin{array}{l}{[145]} \\
{[146]}\end{array}$ \\
\hline & PBMCs & Decrease & L. casei Shirota & [129] \\
\hline \multirow{12}{*}{ IL-10 (Anti-inflammatory) } & \multirow{6}{*}{ PBMCs } & \multirow{6}{*}{ Increase } & Bifidobacteria DNA & $\begin{array}{l}{[147]} \\
{[123]} \\
\end{array}$ \\
\hline & & & Bifidobacteria & {$[142]$} \\
\hline & & & B. longum W11 & {$[127]$} \\
\hline & & & L. fermentum & {$[143]$} \\
\hline & & & $\begin{array}{l}\text { L. acidophilus } \\
\text { L. plantarum strains }\end{array}$ & {$[130]$} \\
\hline & & & $\begin{array}{l}\text { L. acidophilus } \\
\text { L. reuteri } \\
\end{array}$ & {$[132]$} \\
\hline & PBMC-NK cells & Increase & \begin{tabular}{|l|} 
B. bifidum \\
VSL\#3 \\
L. reuteri \\
\end{tabular} & \multirow[t]{2}{*}{$\begin{array}{l}{[147]} \\
{[115]}\end{array}$} \\
\hline & Blood-DCs & Increase & L. plantarum & \\
\hline & Mo-DCs & Increase & $\begin{array}{l}\text { L. casei } \\
\text { L. rhamnosus } \\
\text { Bifidobacteria } \\
\end{array}$ & $\begin{array}{l}{[148]} \\
{[149]}\end{array}$ \\
\hline & Mo-DCs & Increase & \multirow[b]{2}{*}{ B. infantis } & \multirow[b]{2}{*}[150]{} \\
\hline & $\begin{array}{l}\text { Mo-DCs, } \\
\text { mDCs, pDCs }\end{array}$ & Increase & & \\
\hline & PBMCs & Decrease & L. casei Shirota & {$[129]$} \\
\hline
\end{tabular}

Overview of studies documenting the probiotic strain-specific effects on the pro-inflammatory cytokines (TNF $\alpha$, IL-1 $\beta$ and IL-6) and the anti-inflammatory cytokine, IL-10. All studies are human studies utilising a range of cell sources: peripheral blood mononuclear cells (PBMCs), NK cells, DCs, THP-1 pro-monocytic cell line, macrophage subsets and intestinal epithelial cells. 


\section{Immunopathology and Probiotic/Prebiotic Immunomodulation}

\subsection{Th1/Th17-Dominant Pathology, Crohn's Disease}

The balance between humoral and cell mediated immunity is important for a healthy immune response, there are a range of pathologies in which a bias in the cytokine and cell differentiation profile are observed. In these cases a dysbiosis of the gut microbiota is often seen, thus the use of probiotics to counteract this has been the focus of many research papers. The understanding of individual variations in gut flora is widening with the recent advances in DNA sequencing and proteomics technologies, allowing in-depth analysis of the strains present in the human GIT, both in health and disease. There is however often a genetic predisposition which leads to an altered response to bacteria, here we review the mechanisms underlying pathology and the potential for using probiotics and symbiotics as a therapeutic tool. Crohn's is an inflammatory bowel disease, which can affect any part of the GIT; it is characterised by transmural granulomatous inflammation with high expression of IL-12/IL-23 and an associated predominance of $\mathrm{CD}^{+}$Th1/Th17 cells, leading to the secretion of IFN- $\gamma, \mathrm{TNF} \alpha$ and IL-17 [151] (refer to Figure 1).

Th17 cells are a CD4 ${ }^{+}$expressing Th1-like subset, activated by IL-23 and IL-6 to produce IL-17, IL-22 and IL-26 (reviewed in [152]). Pro-inflammatory, Th17s and IL-17 are of growing importance to immunological research due to their emerging role in inflammatory pathologies including rheumatoid arthritis, Crohn's disease, cancer and dermatitis [153]. As probiotics are able to modulate both Th1 and Th2 mediated responses, attention drew to potential use in modulating Th17 cells. Several studies have focussed on probiotic modulation of IL-17 and IL-23. Paolillo et al. [135] found L. plantarum treatment with LPS-activated Caco-2 epithelial cells reduced IL-23, suggested to be a TLR-2 dependent mechanism; a cytokine finding supported by Ghadimi et al. [134] who observed a reduction in IL-17 and IL-23 in PBMCs co-cultured with human intestinal cells and treated with B. breve and L. rhamnosus GG. In contrast, a study using human monocyte-derived DCs found IL-23 to be induced upon treatment with L. rhamnosus [120]. Evrard et al. further found L. rhamnosus to increase CD86 and DC-SIGN expression on human DCs suggesting the effects of Lactobacillus on Th17 activation to be mediated through modulation of DC function [120]. These co-culture system studies are more applicable to in vivo settings; in which case particular probiotic strains may have a role in inducing Th17-mediated immunity through modulation of DCs affecting down-stream pro-inflammatory cytokine expression.

Crohn's sufferers display a shift in commensal bacterial populations towards higher numbers of Gram-negative Proteobacteria and lower numbers of Gram positive Firmicutes, there is also a dysbiosis in the genera Bacteroides with a higher expression of B. ovatus and B. vugatus and lower expression of $B$. uniformis $[154,155]$. It is believed that a dysregulated pro-inflammatory response is elicited in those with genetic mutations in pathogen-sensing receptors such as the CARD15 gene encoding NOD2, a cytosolic protein expressed by epithelial cells, paneth cells, dendritic cells and macrophages and is involved in the sensing of bacterial cell wall peptidoglycan $[156,157]$. The NOD2 pathway is linked to activation and regulation, of NF- $\mathrm{KB}$ and expression of proinflammatory cytokines TNF $\alpha$ IL-1 $\beta$, IL-12 and anti-bacterial peptides, as well as transcription of apoptotic genes. There is some disagreement however, as to the impact mutations may have in Crohn's disease, as there are 
30 function mutations in NOD2 thus the impact on immunity is highly variable $[156,158]$. It would seem that an increase in IL-1 $\beta$ may be partially responsible [156]. Although it has been suggested that NOD2 plays a role in the production of anti-inflammatory IL-10 and TGF- $\beta$ and thus loss of function mutations may result in a loss of tolerance to commensals [159]. It is believed that these mutations, acting in combination with the strains of bacteria present in the GIT, result in an excessive proinflammatory response [158]. As previously noted there is a marked reduction in the numbers of Firmicutes found in the GIT of patients with Crohn's, specifically the beneficial commensal Faecalibacterium prausnitzii [160]. A recent study used this strain as a probiotic both in vivo and in vitro, and found that oral administration of the live bacterium lead to reduced evidence of experimental colitis in mice [160]. A marked increase in IL-10 secretion and significant reduction in IFN $\gamma$ and IL-12 production was seen in PBMC exposed to this probiotic, thus it is suggested as a potential therapeutic strategy in Crohn's disease [160,161]. Interestingly, there could be a correlation between this bacterium and transepithelial resistance as F. prausnitzii is a butyrate producing bacteria, and butyrate is a metabolic source for the catabolism of ATP vital for host epithelial cell metabolism [161,162]. A diet rich in prebiotic short chain fatty acids provides a supporting role for the butyrate-producing commensals $[163,164]$. The dietary prebiotic inulin which is contained in bananas, tomatoes, onions, garlic and Jerusalem artichokes has been shown to be a prime source of nutrients for F. prausnitzii and therefore future developments in the treatment of Crohn's could involve symbiotic preparations of inulin and F. prausnitzii $[165,166]$. (Refer to Table 3).

Table 3. Probiotic strains, prebiotics and synbiotics differentially modulate immunopathology.

\begin{tabular}{|c|c|c|c|}
\hline Pathology & Response & Probiotic/Prebiotic & References \\
\hline \multirow{2}{*}{ Crohn’s } & $\downarrow$ IFN- $\gamma$, IL-12 & F. prausnitzii & {$[160]$} \\
\hline & $\uparrow$ IL-10 & Fructo-oligasaccharides & [167] \\
\hline \multirow{10}{*}{$\begin{array}{l}\text { Ulcerative } \\
\text { colitis }\end{array}$} & \multirow{2}{*}{$\downarrow$ IL- $1 \beta$, TNF- $\alpha$, IFN- $\gamma$, IL-12 } & L. plantarum $299 \mathrm{~V}$ & [168] \\
\hline & & LGG & [169] \\
\hline & $\uparrow$ IL-10 & LGG & [169] \\
\hline & $\downarrow \beta$-defensins, TNF- $\alpha$, IL-1, CRP & B. longum/Synergy 1 & [170] \\
\hline & $\downarrow \mathrm{CRP}$ & B. longum/psyllium & {$[171]$} \\
\hline & $\downarrow$ adherence of B. vulgatas & LGG & [172] \\
\hline & $\downarrow$ expression of tight junction proteins & VSL\#3 & [172] \\
\hline & $\downarrow$ tissue inflammation & VSL\#3 & [173] \\
\hline & $\begin{array}{l}\uparrow \text { no. } \gamma \delta \text { IEL } \\
\downarrow \text { no. } \gamma \delta \text { T-cells in lamina propria } \\
\uparrow \text { no. T-regs }\end{array}$ & $\begin{array}{l}\text { L. acidophilus }+ \\
\text { B. longum }\end{array}$ & [87] \\
\hline & Reshape microbiota composition & VSL\#3 & [174] \\
\hline \multirow{2}{*}{$\begin{array}{l}\text { Colorectal } \\
\text { Cancer }\end{array}$} & $\begin{array}{l}\downarrow \text { aberrant crypt formation } \\
\downarrow \text { cecal } \mathrm{pH}\end{array}$ & $\begin{array}{l}\text { Bifidobacteria }+ \\
\text { Lactobacilli }+ \\
\text { Inulin }+ \\
\text { Oligofructose }\end{array}$ & {$[175]$} \\
\hline & $\begin{array}{l}\uparrow \text { SCFA production } \\
\downarrow \text { IL-2 and iNOS }\end{array}$ & $\begin{array}{l}\text { Bifidobacteria }+ \\
\text { Lactobacilli }+ \\
\text { Inulin }+ \\
\text { Oligofructose }\end{array}$ & {$[176]$} \\
\hline
\end{tabular}


Table 3. Cont.

\begin{tabular}{|c|c|c|c|}
\hline \multirow{5}{*}{$\begin{array}{l}\text { Colorectal } \\
\text { Cancer }\end{array}$} & $\begin{array}{l}\downarrow \mathrm{H}_{2} \mathrm{O}_{2} \\
\downarrow \text { tissue inflammation } \\
\uparrow \text { catalase activity }\end{array}$ & L. lactis & [177] \\
\hline & \multirow{2}{*}{$\downarrow$ IL-2 and iNOS } & B. lactis & [176] \\
\hline & & L. rhamnosus & [178] \\
\hline & $\begin{array}{l}\uparrow \text { angiostatin } \\
\uparrow \text { no. CD4+ T-cells } \\
\uparrow \text { IL-17 and TNF- } \alpha\end{array}$ & VSL\#3 & [179] \\
\hline & $\begin{array}{l}\downarrow \text { CXCR4 mRNA expression } \\
\downarrow \text { MHC-class } 1 \\
\downarrow \text { tumour growth } \\
\uparrow \text { CT-26 cancer cell apoptosis }\end{array}$ & L. acidophilus & [180] \\
\hline \multirow{7}{*}{ Allergy } & $\downarrow$ IL-4 and IL-5 & L. plantarum & [122] \\
\hline & \multirow{2}{*}{$\uparrow \mathrm{IL}-12$ and IFN- $\gamma$} & L. lactis & [181] \\
\hline & & L. plantarum & [128] \\
\hline & $\downarrow$ IL-5, IL-4 and IL-13 & B. breve + oligosaccharide & [182] \\
\hline & $\uparrow$ no. $\mathrm{CD}^{+} \mathrm{CD} 25^{+} \mathrm{Foxp}^{+}{ }^{+}$T-regs & AhR ligand (TCDD) & [89] \\
\hline & $\begin{array}{l}\downarrow \text { IL-12 } \\
\leftrightarrow \text { no. T-regs }\end{array}$ & B. breve + oligosaccharide & [183] \\
\hline & $\begin{array}{l}\uparrow \text { no. bifidobacteria colonies } \\
\downarrow \text { no. Clostridium colonies } \\
\downarrow \text { faecal pH } \\
\leftrightarrow \text { IgE } \\
\leftrightarrow \text { levels of acetic acid }\end{array}$ & B. breve + oligosaccharide & [184] \\
\hline \multirow{4}{*}{ Coeliac } & $\begin{array}{l}\uparrow \text { no. CD4+ T-cells } \\
\uparrow \text { IFN- } \gamma\end{array}$ & L. casei & [185] \\
\hline & $\uparrow$ transepithelial resistance & B. lactis & [186] \\
\hline & $\uparrow$ IL-12 and IFN- $\gamma$ & Shigella CBD8 & [187] \\
\hline & $\uparrow \mathrm{TNF}-\alpha$ & $\begin{array}{l}\text { B. bifidum } \\
\text { L. paracasei } \\
\text { L. fermentum }\end{array}$ & $\begin{array}{l}{[187]} \\
{[188]}\end{array}$ \\
\hline
\end{tabular}

Overview of studies documenting the role of probiotic strains, prebiotics and synbiotic formulations and their effects on Crohn's disease, Ulcerative colitis, colorectal cancer, allergy and coeliac's disease. All studies are human studies detailing potential modulation of a variety of disease markers and immunological functional readouts. Arrows indicate decreases $(\downarrow)$, increases $(\uparrow)$ or no change $(\leftrightarrow)$.

In addition to Th1 cells, Th17 cells are also prevalent in this pathology due to an imbalance in the suppressive Treg population and proinflammatory Th17 cells, with a bias towards the latter. This effectively tips the balance away from tolerogenic Treg activity towards chronic inflammation due to increases in Th1/Th17 and IL-12/23 expression [189,190]. A recent clinical trial used prebiotic fructo-oligosaccharides in Crohn's disease patients and found an increase in the numbers of immune-regulatory dendritic cells and heightened the concentration of IL-10 secreted by intestinal dendritic cells, yet these factors did not reduce the clinical presentation of the disease [167]. A further trial, using a symbiotic combination of Bifidobacterium longum, B. breve and Lactobacillus casei with 
prebiotic psyllium, which comes from barley however, resulted in a significant decrease in clinical scoring of the pathology [191]. Just what the beneficial effects of these symbiotic formulations are to the immunological mechanisms will be a focus of future research endeavours. It can be suggested however, that any beneficial effect would result from immunomodulation of DC/APC function, cytokine production and T-helper differentiation/effector function towards a regulatory/suppressive phenotype.

\subsection{Immunopathology: Th2-Dominant Pathology, Ulcerative Colitis}

Ulcerative Colitis (UC) is an inflammatory bowel disease characterised by diarrheoa, abdominal pain and rectal bleeding. Pro-inflammatory mediators, such as TNF- $\alpha$, are up-regulated in UC, suppression of which has been proven to effectively reduce mucosal damage, colonic infiltration of macrophages and neutrophils and UC-associated tumour growth [192] (refer to Figure 1). As an idiopathic disease, the precise aetiology is unknown however the role of commensal bacteria and dysbiosis has emerged as potential causal factors [193]. Current treatments for IBD include anti-inflammatory drugs, dietary changes and surgery, but with the suggestion of commensal bacteria playing a role in pathogenesis, the therapeutic use of probiotics is being explored.

The rationale behind probiotic therapy lies in the ability to modulate immune response. As UC is a predominant Th2-driven pathology, skewing of the immune response to a more tolerogenic tissue environment may alleviate the damaging effects of a dysregulated inflammatory response. Current therapies do aim to dampen-down these inflammatory responses, however patient responsiveness is variable and surgical procedures invasive; therefore probiotics pose an alternative, non-invasive therapeutic option. Of the studies conducted in UC mouse models, a number of Lactobacillus strains have been identified to modulate pro-inflammatory responses. Both L. plantarum 299v in IL-10 knockout mice [168] and L. rhamnosus GG in transgenic mice [169] have been shown to decrease levels of pro-inflammatory cytokines including IL-1 $\beta$, TNF- $\alpha$, IFN- $\gamma$ and IL-12. Furthermore, levels of the anti-inflammatory cytokine IL-10, was augmented upon administration of L. rhamnosus GG [169]. In addition to direct immunomodulation, Lactobacillus alters epithelial barrier function: L. rhamnosus GG was found to decrease adherence of pathogenic B. vulgatas whereas the probiotic mix VSL\#3 decreased expression of tight junction proteins, occludin, zonulin and claudin and prevented epithelial cell apoptosis in BALB/c mice [172]. VSL\#3 has also been shown to reshape bacterial composition through enhancing species richness and diversity index [174]. In clinical trials, these findings have been related to gross pathological changes, with evidence of decreased tissue inflammation and enhanced disease remission and clinical responsiveness [173,194]. These studies clearly demonstrate the ability of probiotics to modulate the immune response in UC, skewing a predominant pro-inflammatory setting towards a more tolerogenic environment, characterised by down-regulation of pro-inflammatory cytokines such as TNF $\alpha$, IL-1 $\beta$ and IFN $\gamma$ and an up-regulation of anti-inflammatory cytokine IL-10. These effects appear to confer a health benefit, with evidence of enhanced epithelial barrier function, decreased tissue inflammation and a decrease in gross pathology scores (refer to Table 3). Furthermore, bacterial composition variance is emerging as an important factor in overall gut health and the development of gut-associated immune pathologies, with some evidence suggesting habitual consumption of health-promoting bacterial species can alter microbial populations in the gut, preventing UC. 
The health benefit of probiotic co-administration with prebiotics has also been explored in the context of B. longum, which was found to reduce levels of $\beta$-defensins, TNF- $\alpha$, IL- $1 \alpha$ and c-reactive protein (CRP) in a synbiotic ".mix". [170]. In support, a more recent study conducted on UC patients, compared the effects of synbiotics with single probiotic treatment, finding only synbiotic therapy, to significantly suppress CRP levels [171]. In addition, CRP has been found to correlate with disease severity, implying potential use of CRP levels as a marker of UC progression [195]. Therefore if synbiotics act to reduce levels of these pathogenic factors, to an extent greater than probiotics alone, further studies must be conducted to explore optimal combinations of probiotics and prebiotics for therapeutic use.

\subsubsection{Anti-Tumoural Responses and NK Cell Activation}

Natural killer cells (NKs) play a crucial role in tumour surveillance and anti-viral responses. NKs are directly activated by missing or altered self (MHC I), thus responding to suppressive, survival mechanisms elicited by viruses and tumour cells. In addition, NKs are indirectly activated by DCs which secrete soluble factors, such as IL-12, IL-18 and type I interferons. Priming of NKs subsequently leads to killing of tumour cells and the secretion of IFN $\gamma$ and TNF- $\alpha$, both pro-inflammatory cytokines capable of inducing cell-mediated immunity and further activation of antigen-presenting cells (DCs and macrophages) [196] (refer to Figure 1). Interestingly, recent studies have highlighted a role for probiotics in modulating the DC-NK interaction and subsequent anti-tumour immune responses.

Probiotic Lactobacillus strains induce human PBMC secretion of pro-inflammatory cytokines, IL-12 and TNF $\alpha$ [121]. This has since been identified to be a DC-NK mediated immune response. Probiotic Lactobacillus casei Shirota (LcS) induces IL-12 and TNFa production which positively correlated to NK activity $[125,129]$. DC secretion of IL-12 primes NK activation and the subsequent secretion of TNF- $\alpha$, therefore LcS may indirectly activate NK effector function via DCs. This potential probiotic mechanism was further proven by studies finding Lactobacillus strains induced APC production of IL-12, leading to NK activation and NK-derived IFN $\gamma$ secretion, which not only has implications to innate responses but also CMI-mediated anti-tumour responses [114,132]. Lactobacillus-induced IL-12 however, was found to be abrogated in favour of enhanced IL-10 production, (favouring an immune-suppressive, pro-tumoral environment), by the probiotic, Bifidobacterium, suggesting combinatory probiotic therapy may be counter-productive to immunomodulation, in the context of NK-mediated immunity [132]. This further highlights a generalised distinction between probiotic strains, suggesting Lactobacillus predominantly induces a cytotoxic innate immune response (anti-tumour responses) whereas Bifidobacterium play a more regulatory role that may involve priming of regulatory T-cells (pro-tumoural responses).

\subsubsection{Colorectal Cancer}

Since the early work of Rudolph Virkchow in the 1800s, evidence has been accumulated supporting the hypothesis that chronic inflammation is important in cancer development. As inflammation contributes largely to the development and progression of ulcerative colitis (UC), mechanistic links have been made between ulcerative colitis and the development of colorectal cancer (CRC). 
Up-regulation of pro-inflammatory cytokines has been characterised in both UC and CRC [197] and development of CRC occurs within the same tissue site as UC; the chronic inflammation and subsequent tissue damage observed in UC may therefore be causing CRC. As probiotics and synbiotics have both been identified as potentially therapeutic, a similar therapeutic approach could be used for CRC.

Although precise immunomodulatory mechanisms are yet to be clearly defined for probiotics in the context of CRC, probiotics have been found to modulate some pro-inflammatory molecules. A recent study highlighted $L$. lactis as capable of decreasing levels of hydrogen peroxide $\left(\mathrm{H}_{2} \mathrm{O}_{2}\right)$ and enhancing catalase activity, resulting in decreased colonic damage and tissue inflammation, in a BALB/c mouse model [177]. Reactive oxygen species (ROS), such as hydrogen peroxide, are known to contribute to carcinogenesis and metastasis as part of the pro-inflammatory immune response, thus suggesting probiotics are able to target other inflammatory mediators as well as cytokines. Furthermore, L. acidophilus induced a decrease in mRNA expression of stromal-derived factor-1 receptor, CXCR4, suggesting a role in cancer metastasis prevention; on the down side however, also suppressed MHC-class I expression [180]. As antigen presenting cells (APCs) use MHC-I molecules to present antigen to $\mathrm{CD}^{+} \mathrm{Tc}$, an important component of tumour surveillance, the findings of Chen et al., present a potential drawback to the use of L. acidophilus. Activation of $\mathrm{CD} 8^{+} \mathrm{Tc}$ is desirable within the tumour microenvironment due to their anti-tumoural, cytotoxic characteristics; therefore, probiotic-mediated down-regulation of $\mathrm{CD}^{+} \mathrm{Tc}$ activation may perpetuate tumour growth and survival. In terms of gross pathology, L. acidophilus has been found to decrease tumour growth by $50 \%$ in comparison to non-treated mice and enhance the apoptosis of CT-26 cancer cells [180], suggesting the immunomodulatory effects of probiotic administration does have an impact on tissue ultrastructure.

In addition to inhibiting pro-inflammatory mediators, the Lactobacillus mix VSL\#3 was found to increase angiostatin, the endogenous inhibitor of angiogenesis and regulatory T-cells, in DSS-induced CRC mice [179]. In contrast, the study also observed an increase in the number of memory CD4 ${ }^{+}$ T-cells and pro-inflammatory cytokines, IL-17 and TNF $\alpha$. As cancer is a complex disease with evidence suggesting both pro- and anti-inflammatory mechanisms contributing to cancer progression, the varied immunomodulatory roles of probiotics suggests precise strain selection is required for accurate targeting of immune function in different pathologies including colorectal cancer. The stage of development of colorectal cancer may be the determining factor as to which probiotic strain is used.

As diet is an important risk factor in susceptibility to $C R C$, with vitamin $\mathrm{D}_{3}$ and retinoic acid inferring positive effects [198] and heterocyclic amines in red meat acting as mutagens [199,200]; modulation of the dietary composites within the gastrointestinal tract, suggests scope for intervention with prebiotic substrates. As prebiotics are also known to work synergistically with probiotics to elicit beneficial effects on commensal populations and overall gut health, synbiotics have been explored as potential therapeutic agents in CRC. Studies using bifidobacteria and Lactobacillus strains in conjunction with prebiotics, such as inulin and oligofructose, have been found to off-set carcinogenesis. Evidence demonstrating inhibition of aberrant crypt formation, reduction of caecal $\mathrm{pH}$ [175] and increased short chain fatty acid (SCFA) production [176], suggests probiotics could be acting through a range of mechanisms. Direct immune modulation has also been found with B. lactis 
and L. rhamnosus which were shown to decrease IL-2 and inducible NO synthase, the enzyme responsible for nitric oxide production [176,178].

Collectively these studies highlight an important role for probiotics in modulation of pro-inflammatory and pro-tumoural immune responses (refer to Table 3). As colorectal cancer can arise from untreated colitis, these studies suggest potential use of probiotics as an anti-inflammatory therapeutic, utilised not only in pre-established colorectal cancer cases, but also as a preventative measure in patients exhibiting symptomatic signs of colitis or early-stage colorectal cancer. Furthermore, some experimental evidence suggests an important role for prebiotics, highlighting possible functional dependency of probiotics on prebiotic supplementation.

\subsection{Immunopathology: Hypersensitivity}

\subsubsection{Allergy \& Type I Hypersensitivity}

Dysbiosis in the human gut is not only seen in gastrointestinal tract pathology but is also associated with disease at distal sites such as the airways of the lungs [201] and the skin [202,203]. Cross-talk between the microbiota and immune cells located in the mucosa and lamina propria not only primes and tolerises cells locally, but may initiate migration away from the gut towards the mesenteric lymph nodes and other lymphoid tissues inducing systemic immunomodulatory effects [204].

Hypersensitivity immune responses are undesirable over-exuberant immune responses mounted to an allergic antigen, or allergen. Hypersensitivity responses are categorised in accordance to the time taken for an immune response to be mounted and the effector cells and mediators involved. Type-1 hypersensitivity involves an anaphylactic response rapidly initiated to allergenic exposure. This response is predominated by mast cells and basophils, both granulocytes capable of secreting vasoactive amines, such as histamines, upon activation of its high-affinity Fc receptors by IgE (refer to Figure 1). This type of hypersensitivity also involves Th2 cell-derived mediators such as IL-4, IL-5 and IL-13, which induce immunoglobulin class switching to IgE. Modulation of this response, via T-cell subset skewing (e.g., Th2 to Th1 or enhancement of Treg), is a desirable therapeutic approach to allergic pathologies, such as atopic dermatitis and food hypersensitivity, modulatable by probiotic administration.

A number of clinical studies examining differences in microflora between children who displayed early symptoms of atopy and healthy controls, showed a higher prevalence of Clostridia and Bacteroides but lower comparative numbers of Lactobacilli and bifidobacteria [205,206]. Although lactic acid bacteria have been shown to attenuate atopic dermatitis development in mice in a strain dependent manner [207,208], there appears to be little significant effect on human infants already displaying symptoms [209]. Further investigation in animal studies [210,211] and human clinical trials [212,213] has suggested that there may be a window of oportunity in early life before weaning in which probiotic therapy is of use in prevention. This positive probiotic effect arises as a consequence of immune education to microbes and the establishment of a more balanced immune system in the context of Th1, Th17 and Th2 responses.

Current treatments for allergic diseases such as asthma and food allergy are limited to management of the conditions, rather than cure. Probiotic immunomodulation is an attractive strategy with 
which to counterbalance Th2-skewed immune responses associated with allergy. In vitro studies using human peripheral blood mononuclear cells (PBMCs) from allergic patients have shown reduced expression of Th2-associated cytokines (IL-4 and IL-5) on stimulation with total extract of Dermatophagoides pteronyssinus (house dust mite) and prior treatment with lactic acid bacteria strains such as Lactobacillus plantarum [122]. Both Lactococcus lactis and Lactobacillus plantarum, induce high levels of IL-12 and IFN $\gamma$, suppressing Th2 differentiation [128,181]. In contrast, suppression of contact dermatitis in mice has been shown to be mediated by a Lactobacillus acidophilus L92-dependent generation of Tregs [214]. This effect is thought to result from strain-dependent tolerisation of DCs, increasing suppressor activity of natural Tregs as well as inducing Foxp3 ${ }^{+}$ conversion through high expression of IL-10, TGF $\beta$, COX-2 and indoleamine 2,3-dioxygenase [215,216].

Several studies, focussing on probiotic administration in type-1 hypersensitivity responses, revealed inhibitory characteristics for both Lactobacillus and Bifidobacterium strains. Mouse models have demonstrated the ability of $L$. casei and B. longum to inhibit IgE production [217-219]. Inhibition of antibody production prevents binding to Fc receptors on mast cells, thus inhibiting the secretion of vasoactive amines, such as histamines, and other inflammatory mediators, such as TNF- $\alpha$. Indeed, histamine content was found to be decreased in Bifidobacterium treated rats [220] and TNF- $\alpha$ production was found to be inhibited by another Lactobacillus strain, L. reuteri [144], further supporting the role of probiotics in inhibiting mast cell effector function. Systemically, the inhibition of mast cell effector function by probiotics has been associated with preventable anaphylaxis [217]. The inhibition of IgE production is thought to be a consequence of direct action by probiotics on Th2 cells or APCs, which prime B-cell activation and class-switching. A large body of evidence demonstrates a role for Lactobacillus and Bifidobacterium strains in decreasing the levels of secreted IL-4 and IL-5. Both cytokines are Th2-derived, with IL-4 acting on B-cells to induce class-switching and on mast cells to induce degranulation and further cytokine production, and IL-5 inducing eosinophil degranulation. Specific strains found to inhibit IL-4 and IL-5 production include L. casei [219], L. rhamnosus [128], B. longum [218] and B. infantis [220]; see Table 1.

The effects of probiotics on type-I hypersensitivity responses have been further explored by a few studies, in terms of modulation of receptor expression and associated intracellular signalling cascades. Dev et al. [220] found the probiotic mix ( $\mathrm{LacB}$ ) composed of B. longum and B. infantis, inhibited the increase in histamine receptor-1 and histidine decarboxylase (HDC) expression and activity. Furthermore, histamine-2, known to inhibit hypersensitivity responses through activation of cAMP and increased intracellular calcium levels, was augmented by L. reuteri [144]. In addition, L. casei treatment in mice inhibited IgE production by inhibition of Syk/Lyn and MAPK signalling [219]. This provides some insight into probiotic targeting; suggesting probiotics mediate their anti-hypersensitivity effects through direct modulation of APC intracellular signalling with knock-on effects to down-stream effector cell priming. Unlike other probiotic immunomodulatory effects, there seems to be a commonality across probiotic strains in relation to its impact on hypersensitivity responses; whether the strain is Lactobacillus or Bifidobacterium derived, the immune response is shifted from a predominant Th2 response. Probiotics therefore may have a useful application in Th2-dominant pathologies whereby unnecessary immune responses are mounted against self or non-pathogenic antigens, such as atopic dermatitis or allergy. 
Discrepancies have been seen in experiments testing the effectiveness of synbiotic mixtures. Bifidobacterium breve and oligosaccharide treatment used in a cohort of 29 patients with asthma, found a decrease in IL-5, IL-4 and IL-13 [182], yet the same synbiotic mix tested in atopic dermatitis infants found no significant difference in IL-5 levels. Furthermore, in response to allergen-specific stimuli, decreases in IL-12 production were found in conjunction with unchanging levels of Tregs [183]. Previously, an extensive study in a cohort of 90 infants, receiving the same synbiotic treatment, showed an increase in the number of faecal bifidobacteria and a decrease in the number of Clostridium colonies accompanied by a decrease in faecal $\mathrm{pH}$; no significant changes were found in levels of $\operatorname{IgE}$ or the SCFA, acetic acid [184]. This study however did permit the use of topical corticosteroids during the experiment; a confounding variable that could have altered the effects of synbiotics on immune modulation. Thus, probiotics and synbiotics represent an efficacious approach to the control of hypersensitivity/allergy (refer to Table 3). There is a need to characterise immune hypersensitivity reactions and their modulation by these pro- and syn-biotics, as future use of these in the treatment of allergy will require an appreciation for strain variations in determining immune suppression or immune-deviation. The requirement for which will vary according to specific allergens and hypersensitivity.

\subsubsection{Coeliac Disease}

At the other extreme of allergic responses is delayed type hypersensitivity (DTH) which includes the condition Coeliac disease, although this pathology encompasses many aspects of hypersensitivity reactions which culminate in an autoimmune-like disorder. This disease is associated with the gut mucosa triggered by an inappropriate immune response to the dietary antigen gluten ( $\alpha$-gliadin), more specifically toxic peptide elements resistant to proteolytic breakdown, in individuals who express the (HLA-DQ2/DQ8) antigen presenting molecule [187,221]. In this way, gliadin-derived peptides are presented to naïve and Th1 cells inducing secretion of IFN $\gamma$; additionally, gliadin-derived peptides ( $\alpha$-gliadin p31-43/49) induce high-level expression of membrane-bound IL-15 on intestinal epithelial cells inducing infiltration of intraepithelial lymphocytes [222-224]. IL-15 induces the expression of MICA by physiologically stressed intestinal epithelial cells, promoting the infiltration of NK cells and intraepithelial lymphocytes expressing the NKG2D receptor, resulting in the lysis of epithelial cells and the breakdown of the mucosal barrier, hence villous atrophy characteristic of coeliac disease [224-227] (refer to Figure 1). It has been shown that high levels of TNF $\alpha$ and IL-18, with surprisingly little IL-12, exist in people with this Th1-biased condition; IL18 drives the transcription factor $\mathrm{T}$ bet and thus induces naïve $\mathrm{T}$ helper cell differentiation towards Th1 [228]. The mechanisms underpinning this complex hypersensitivity type IV-predominated pathology are further complexed by the observations that antibodies play a role in this pathology; sIgA facilitates trancytosis of gliadin peptides across the epithelial barrier and autoantibodies (IgA and $\operatorname{IgG}$ ) recognising tissue transglutaminase, normally involved in the breakdown of gliadin at the epithelial apical surface [229-231].

Coeliac patients have a dysbiosis in their gut microflora with lower variation in beneficial commensal strains of Bifidobacterium and the atypical expression of Leuconostoc mesenteroides and L. carnosum along with Lactobacllius curvatus, believed to be characteristic of coeliac 
patients $[232,233]$. The strain Bifidobacterium longum was significantly lower in coeliac patients than controls, whereas B. bifidum was higher in those with active disease [233]. Thus, a recent study looked at the effects of various bacterial strains isolated from coeliac patients on co-cultures of Caco-2 cells and PBMCs in the presence of the antigen gliadin and cytokine trigger IFN $\gamma$, then examined for cytokine release [187]. The bacterium Shigella CBD8 was found to induce higher secretion of IL-12 and IFN $\gamma$ in the presence of gliadin than stimulation with antigen alone, whereas stimulation with the strains Bifidobacterium bifidum induced higher levels of TNF- $\alpha$ than the other bacterial strains [187]. Thus strains present in the coeliac gut could either reduce disease risk or enhance the proinflammatory response to gliadin, and that the high levels of gram negative bacteria with fewer bifidobacteria than healthy individuals could be partially responsible for the disease pathogenesis [187]. To this end, the live strains of Bifidobacterium lactis and Lactobacillus fermentum were co-cultured with Caco-2 cells exposed to gliadin to monitor changes in transepithelial resistance; results demonstrated that $B$. lactis counteracted the effects of gliadin on TER, whereas L. fermentum had no effect at preventing increased permeability [186]. A recent review by Silano et al., [234] discusses the fact that there appears to be a similar timing mechanism involved in the development of coeliac disease as is seen for nut allergy. There would appear to be a time-period in infancy where the risks associated with gluten intolerance can be minimised during weaning, the risk is increased before 3 months of age and after 7 months of age, it is also known that breast-feeding during the weaning period onto gluten halves the risk of developing coeliac disease.

Due to the variable immunological nature of coeliac disease, the use of probiotics is rather complex and associated impacts are hard to monitor experimentally (refer to Table 3). Studies using gliadin-immunised human HLA-DQ8 transgenic mice, found that two different strains of probiotic Lactobacillus paracasei and Lactobacillus fermentum increased the levels of antigen-specific TNF- $\alpha$, and Lactobacillus casei induced a strong increase in $\mathrm{CD}^{+} \mathrm{T}$ cell population and IFN $\gamma$ secretion [185,188]. However, it was later discovered that the administration of this L.casei in a murine NSAID-induced intestinal injury model, again expressing the HLA-DQ8 transgene, in fact had a preventative effect on villous atrophy, yet this effect was only mediated with prolonged use of the probiotic [235]. The literature available regarding the use of prebiotics as a therapy in this pathology is scarce. The accepted treatment for coeliac disease however, involves avoidance of dietary gluten and the use of inulin in gluten-free bread is being introduced as a method for producing wheat replacement foods with an improved consistency in order to help individuals adhere to the strict dietary regime [236]. Such use of the prebiotic, inulin, is likely to have an effect on the gut microbiota, potentially redressing the dysbiosis observed with this hypersensitivity-associated pathology.

\section{Future Perspectives}

This review has gone some way in highlighting the complexity of mechanistic effects elicited by the use of probiotics in the modulation of the human immune system. In the context of homeostatic gut mucosa and microbiota, the use of probiotics and indeed combination with prebiotics acts as a regimen for long health. In the case of gut pathology, whether inflammatory bowel disease, colorectal cancer or hypersensitivity, the use of prebiotics and probiotics in combination can have dramatic effects on the immune system, hence immunopathology. Future developments will only surface upon more extensive 
research into the mechanism underpinning these immunopathologies and how they may be modulated by prebiotics, probiotics and synbiotics. There are many areas of interest that can be mentioned; some which may be considered however, include (i) the role of pre-/probiotic modulators in immunosenescence, (ii) modulation of APC function, in particular mucosal macrophages, (iii) probiotic bacterial products (cell wall-associated and secreted) and finally, (iv) faecal transplantation.

Immunoscenescence: it is well established that the immune system deteriorates with old age. This includes thymic atrophy, hence reduction in overall $\mathrm{T}$ cell responses and a reduction in numbers and activity of NK cells [237,238]. Both these compartments of the immune system are vital to tumour surveillance; a reduction in which increases the prevalence of cancer in old age. Studies are surfacing which are focussing in on the ability of probiotics to augment the activity of DCs, NK cells and $\mathrm{CD}^{+} \mathrm{Tc}$ with some impressive results; responses not otherwise observed in healthy, younger populations [129,239].

Mucosal macrophages: represent an important APC, which remain resident in the responding tissue, as such are able to directly modulate local T cell, B cell, NK, DC, IEL and mast cell responses. There is an established literature for macrophage effector subsets, where type I macrophages are pro-inflammatory and type II are anti-inflammatory/regulatory. Manipulation of macrophage plasticity through probiotics, their secreted products and prebiotics, hold potential for harnessing their differential effector responses in the treatment of gut mucosal inflammatory bowel diseases, gut cancer and hypersensitivity (reviewed in [138]).

Probiotic bacterial products: probiotic bacteria may exert their immune-modulatory activity either by direct interaction of the bacterial cell with host immune cells or via secretable products. With the vast proliferation of the pattern recognition receptor literature, interest is growing with respect to characterising the commensal-associated molecular patterns (CAMPs). These patterns are already being described for their immunomodulatory functionality and include cell wall components such as Lactobacillus plantarum lipoteichoic acid, which exhibits anti-inflammatory effects [240,241] and C-type lectins, which interact with DC-SIGN on DCs, resulting in the induction of Tregs [115]. Finally, the characterisation of the lactobacillus, exoproteosome, is likely to introduce many secretable immunomodulatory molecules (reviewed in [242]).

Faecal transplantation: It is generally considered that the GIT microbiota of healthy adults remains in a stable state of eubiosis. However as work continues on probiotic research, it is increasingly apparent that factors such as mode of delivery and feeding regimen in early life in conjunction with host genetics, antibiotic usage and life style, influence the composition of the microbiota making it genetically and metabolically unique to the individual [243]. The extent of this variation is likely to be the primary source of inconclusive results from clinical trials testing prebiotic/probiotic/symbiotic formulations in humans, as one person's microbial balance may not suit another. Yatsunenko et al., [244], revealed that GIT microbial composition is most alike between cohabiting individuals compared to those from other families. This similarity may provide a unique resource for rebooting the GIT microbiota resulting in alleviation of disease associated with microbial dysbiosis. Allogenic faecal transplantation has been successfully used in the resolution of $C$. difficile infections [245] and presents promise for the management of symptoms in IBD patients [245]. Furthermore, faecal transplantation may provide a strategy to prevent or treat inappropriate immune responses at sites distal to the GIT, 
such as those seen in asthma and allergic rhinitis, through Th1-mediated cross-regulation of Th2 responses and generation of Tregs, which may suppress effector T cells mobilised in allergy.

\section{Conclusions}

In addition to playing an important role in barrier defence, probiotics have an ever-unfolding role to play in the modulation of mucosal immunity. Probiotic bacteria can modulate the activity of many cells of the immune system, including innate system NKs, DCs, macrophages, epithelial cells and granulocytes, as well as adaptive system Th1, Th2, Th17, Treg, Tc and B cells. Thus, probiotic bacteria have the potential to modulate any part of the immune system in the context of acute responses to intracellular or extracellular pathogens or chronic responses observed in dysregulated immunopathological conditions such as IBD, colorectal cancer and hypersensitivity. Modulation of immunopathology to the advantage of the human host can only realistically occur upon a full knowledge of the modulatory capabilities of the probiotic and a full appreciation of the mechanisms underpinning the pathology. Probiotic bacterial strains can be generalised to exert immune-activation, -deviation or -regulation/suppression responses. Thus, selection of probiotic strains, and indeed combinations of probiotics, will be formulated upon careful consideration of the disease mechanisms and the desired immunomodulatory effect. Finally, the growing body of evidence for the suitability of prebiotics in immunomodulation and formulation with probiotic strains, as synbiotics, represents a realistic approach in disease modification. The probiotic species acting as a quick-fix immunomodulatory "plaster" and the prebiotic facilitating commensal organisms, modulating the dysbiosis in the gut microbiota and further modifying the immune system to our benefit-healing from within!!

\section{Conflict of Interest}

The authors declare no conflict of interest.

\section{References}

1. FAO/WHO. Guidelines for the Evaluation of Probiotics in Food, 2002. Available online: ftp://ftp.fao.org/es/esn/food/wgreport2.pdf (accessed on 1 May 2013).

2. Maurice, C.F.; Haiser, H.J.; Turnbaugh, P.J. Xenobiotics shape the physiology and gene expression of the active human gut microbiome. Cell 2013, 152, 39-50.

3. Bentley, R.; Meganathan, R. Biosynthesis of vitamin K (menaquinone) in bacteria. Mircobiol. Rev. 1982, 46, 241-280.

4. Nilsson, A.C.; Östman, E.M.; Holst, J.; Björk, I.M. Including indigestible carbohydrates in the evening meal of healthy subjects improves glucose tolerance, lowers inflammatory marks, and increases satiety after subsequent standardized breakfast. J. Nutr. 2008, 138, 732-739.

5. Matsumoto, M.; Ishige, A.; Yazawa, Y.; Kondo, M.; Muramatsu, K.; Watanabe, K. Promotion of intestinal peristalsis by Bifidobacterium spp. Capable of hydrolysis sennosides in mice. PLoS One 2012, 7, e31700. 
6. Candela, M.; Perna, F.; Carnevali, P.; Vitali, B.; Ciati, R.; Gionchetti, P.; Rizzello, F.; Campieri, M.; Brigidi, P. Interaction of probiotic Lactobacillus and Bifidobacterium strains with human intestinal epithelial cells: Adhesion properties, competition against enteropathogens and modulation of IL-8 production. Int. J. Food Microbiol. 2008, 125, 286-292.

7. Mazmanian, S.K.; Lui, C.; Tzianaboz, A.O.; Kasper, D.L. An immunomodulatory molecule of symbiotic bacteria directs maturation of the host immune system. Cell 2005, 122, 107-118.

8. Zschüttig, A.; Zimmermann, K.; Blom, J.; Goesmann, A.; Pöhlmann, C.; Gunzer, F. Identification and characterisation of Microcin S, a new antibacterial peptide produced by probiotic Escherichia coli G3/10. PLoS One 2012, 7, e33351.

9. Gibson, G.R.; Roberfroid, M.B. Dietary modulation of the human colonic microbiota: Introducing the concept of prebiotics. J. Nutr. 1995, 125, 1401-1412.

10. Van Zanten, G.C.; Knudsen, A.; Röytiö, H.; Forssten, S.; Lawther, M.; Blennow, A.; Lahtinen, S.J.; Jakobsen, M.; Svensson, B.; Jespersen, L. The effect of selected synbiotics on microbial composition and short-chain fatty acid production in model system of the human colon. PLoS One 2012, 7, e47212.

11. Knol, J.; Scholtens, P.; Kafka, C.; Steenbakkers, J.; Gro, S.; Helm, K.; Klarczyk, M.; Schöpfer, H.; Böckler, H.M.; Wells, J. Colon microflora in infants fed formula with galacto- and fructo- oligosaccharides: More like breast-fed infants. J. Pediatr. Gastroenterol. Nutr. 2005, 40, $36-42$.

12. Holscher, H.D.; Faust, K.L.; Czerkies, L.A.; Litov, R.; Ziegler, E.E.; Lessin, H.; Hatch, T.; Sun, S.; Tappenden, K.A. Effects of prebiotic-containing infant formula on gastrointestinal tolerance and fecal microbiota in a randomized controlled trial. JPEN J. Parenter. Enteral Nutr. 2012, 36, 95S-105S.

13. Roberfroid, M.; Gibson, G.R.; Hoyles, L.; McCartney, N.L.; Rastall, R.; Rowland, I.; Wolvers, D.; Watzl, B.; Szajewska, H.; Stahl, B.; et al. Prebiotic effects metabolic and health benefits. Br. J. Nutr. 2010, 104, S1-S63.

14. Yazawa, K.; Imai, K.; Tamura, Z. Oligosaccharides and polysaccharides specifically utilizable by bifidobacteria. Chem. Pharm. Bull. 1978, 26, 3306-3311.

15. Mitsuoak, T.; Hidaka, H.; Eida, T. Effect of fructo-oligosaccharides on intestinal microflora. Nahrung 1987, 31, 427-436.

16. Nepelska, M.; Cultrone, A.; Béguet-Crespel, F.; Le Roux, K.; Doré, J.; Arulampalam, V.; Blottière, H.M. Butyrate produced by commensal bacteria potentiates phorbol esters induced AP-1 response in human intestinal epithelial cells. PLoS One 2012, 7, e52869.

17. Ohigashi, S.; Sudo, K.; Kobayashi, D.; Takahashi, O.; Takahashi, T.; Asahara, T.; Nomoto, K.; Onodera, $\mathrm{H}$. Changes of the intestinal microbiota, short chain fatty acids and fecal $\mathrm{pH}$ in patients with colorectal cancer. Digest. Dis. Sci. 2013, in press.

18. Whitman, W.B.; Coleman, D.C.; Wiebe, W.J. Prokaryotes: The unseen majority. Proc. Natl. Acad. Sci. USA 1998, 95, 6578-6583.

19. Bäckhed, F.; Ley, R.E.; Sonnenburg, J.L.; Peterson, D.A.; Gordon, J.I. Host-bacterial mutualism in the human intestine. Science 2005, 307, 1915-1920. 
20. Gill, S.R.; Pop, M.; DeBoy, R.T.; Eckburg, P.B.; Turnbaugh, P.J.; Samuel, B.S.; Gordon, J.I.; Relman, D.A.; Fraser-Liggett, C.M.; Nelson, K.E. Metagenomic analysis of the human distal gut microbiome. Science 2006, 312, 1355-1359.

21. Eckburg, P.B.; Bik, E.M.; Bernstein, C.N.; Purdom, E.; Dethlefsen, L.; Sargent, M.; Gill, S.R.; Nelson, K.E.; Relman, D.A. Diversity of the human intestinal microbial flora. Science 2005, 308, 1635-1638.

22. Qin, J.; Li, R.; Raes, J.; Arumugam, M.; Burgdorf, K.S.; Manichanh, C.; Nielsen, T.; Pons, N.; Levenez, F.; Yamada, T.; et al. A human gut microbial gene catalogue established by metagenomic sequencing. Nature 2010, 464, 59-65.

23. Penders, J.; Thijs, C.; Vink, C.; Stelma, F.F.; Snijders, B.; Kummeling, I.; van den Brandt, P.A.; Stobberingh, E.E. Factors influencing the composition of the intestinal microbiota in early infancy. Paediatrics 2006, 118, 511-521.

24. Biasucci, G.; Benenati, B.; Morelli, L.; Bessi, E.; Boehm, G. Cesarean delivery may affect the early biodiversity of intestinal bacteria. J. Nutr. 2008, 138, 1796S-1800S.

25. Huurre, A.; Kalliomäki, M.; Rautava, S.; Rinne, M.; Salminen, S.; Isolauri, E. Mode of delivery-Effects on gut microbiota and humoral immunity. Neonatology 2008, 93, 236-240.

26. Liao, Y.; Jiang, R.; Lönnerdal, B. Biochemical and molecular impacts of lactoferrin on small intestinal growth and development. Biochem. Cell Biol. 2012, 90, 476-484.

27. Martín, R.; Langa, S.; Reviriego, C.; Jimínez, E.; Marín, M.L.; Xaus, J.; Fernández, L.; Rodríguez, J.M. Human milk is a source of lactic acid bacteria for the infant gut. J. Pediatr. 2003, 143, 754-758.

28. Martín, R.; Jiménez, E.; Heilig, H.; Fernández, L.; Marín, M.L.; Zoetendal, E.G.; Rodríguez, J.M. Isolation of bifidobacteria from breast milk and assessment of the bifidobacterial population by PCR-denaturing gradient gel electrophoresis and quantitative real-time PCR. Appl. Environ. Microbiol. 2009, 74, 965-969.

29. Albesharat, R.; Ehrmann, M.A.; Korakli, M.; Yazaji, S.; Vogel, R.F. Phenotypic and genotypic analyses of lactic acid bacteria in local fermented food, breast milk and faeces of mothers and their babies. Syst. Appl. Microbiol. 2011, 34, 148-155.

30. Martín, R.; Langa, S.; Reviriegoa, C.; Jiméneza, E.; Marína, M.L.; Olivaresb, M.; Bozab, J.; Jiménezb, J.; Fernándeza, L.; Xausb, J.; et al. The commensal microflora of human milk: New perspectives for food bacteriotherapy and probiotics. Trends Food Sci. Technol. 2004, 15, 121-127.

31. Garrido, D.; Nwosu, C.; Ruiz-Moyano, S.; Aldredge, D.; German, J.B.; Lebrilla, C.B.; Mills, D.A. Endo- $\beta$-N-acetylglucosaminidases from infant gut-associated bifidobacteria release complex N-glycans from human milk glycoproteins. Mol. Cell. Proteomics 2012, 11, 775-785.

32. Yolken, R.H.; Peterson, J.A.; Vonderfecht, S.L.; Fouts, E.T.; Midthun, K.; Newburg, D.S. Human milk mucin inhibits rotavirus replication and prevents experimental gastroenteritis. J. Clin. Invest. 1992, 90, 1984-1991.

33. Dobson, A.; Crispie, F.; Rea, M.C.; O’Sullivan, O.; Casey, P.G.; Lawlor, P.G.; Cotter, P.D.; Ross, P.; Gardiner, G.E.; Hill, C. Fate and efficacy of lacticin 3147-producing Lactococcus lactis in the mammalian gastrointestinal tract. FEMS Microbiol. Ecol. 2011, 76, 602-614. 
34. Yu, Z.T.; Chen, C.; Kling, D.E.; Liu, B.; McCoy, J.M.; Merighi, M.; Heidtman, M.; Newburg, D.S. The principal fucosylated oligosaccharides of human milk exhibit prebiotic properties on cultured infant microbiota. Glycobiology 2013, 23, 169-177.

35. Eggesbø, M.; Moen, B.; Peddada, S.; Baird, D.; Rugtveit, J.; Midtvedt, T.; Bushel, P.R.; Sekelja, M.; Rudi, K. Development of gut microbiota in infants not exposed to medical interventions. APMIS 2011, 119, 17-35.

36. Savino, F.; Roana, J.; Mandras, N.; Tarasco, V.; Locatelli, E.; Tullio, V. Faecal microbiota in breast-fed infants after antibiotic therapy. Acta Paediatr. 2011, 100, 75-78.

37. Bartizal, K.F.; Wostmann, B.S.; Wagner, M. Distribution and effects of a defined six-member murine derived microflora in gnotobiotic gerbils. Appl. Environ. Microbiol. 1984, 47, 746-751.

38. Pollard, M.; Sharon, N. Responses of the Peyer's patches in germ-free mice to antigenic stimulation. Infect. Immun. 1970, 2, 96-100.

39. Williams, A.M.; Probert, C.S.; Stepankova, R.; Tlaskalova-Hogenova, H.; Phillips, A.; Bland, P.W. Effects of microflora on the neonatal development of gut mucosal $\mathrm{T}$ cells and myeloid cells in the mouse. Immunology 2006, 119, 470-478.

40. Yamamoto, M.; Yamaguchi, R.; Munakata, K.; Takashima, K.; Nishiyama, M.; Hioki, K.; Ohnishi, Y.; Nagasaki, M.; Imoto, S.; Miyano, S.; et al. A microarray analysis of gnotobiotic mice indicating that microbial exposure during the neonatal period plays an essential role in immune system development. BMC Genomics 2012, 13, 335.

41. Rhee, K.; Sethupathi, P.; Dirks, A.; Lanning, D.K.; Knight, K.L. Role of commensal bacteria in development of gut-associated lymphoid tissues and preimmune antibody repertoire. J. Immunol. 2004, 172, 1118-1124.

42. Russell, S.L.; Gold, M.J.; Willing, B.P.; Thorson, L.; McNagny, K.M.; Finlay, B.B. Perinatal antibiotic treatment affects murine microbiota, immune responses and allergic asthma. Gut Microbes 2013, 4, 158-164.

43. King, C.; Sarvetnick, N. The incidence of type-1 diabetes in NOD mice is modulated by restricted flora not germ-free conditions. PLoS One 2011, 6, e17049.

44. Ochoa-Repáraz, J.; Mielcarz, D.W.; Wang, Y.; Begum-Haque, S.; Dasgupta, S.; Kasper, D.L.; Kasper, L.H. A polysaccharide from the human commensal Bacteroides fragilis protects against CNS demyelinating disease. Mucosal Immunol. 2010, 3, 487-495.

45. Strachan, D.P. Hay fever, hygiene, and household size. Br. Med. J. 1989, 299, 1259-1260.

46. Aumeunier, A.; Grela, F.; Ramadan, A.; Pham Van, L.; Bardel, E.; Gomez Alcala, A.; Jeannin, P.; Akira, S.; Bach, JF.; Thieblemont, N. Systemic Toll-like receptor stimulation suppresses experimental allergic asthma and autoimmune diabetes in NOD mice. PLoS One 2010, 5, e11484.

47. Gross, F.; van der Meulen, J.; Snel, J.; van der Meer, R.; Kleerebezem, M.; Niewold, T.V.; Hulst, M.M.; Smiths, M.A. Mannose-specific interaction of Lactobacillus plantarum with porcine jejunal epithelium. FEMS Immunol. Med. Microbiol. 2008, 54, 215-223.

48. Wilson, K.H.; Perini, F. Role of competition for nutrients in suppression of Clostridium difficile by the colonic microflora. Infect. Immun. 1988, 56, 2610-2614. 
49. Maltby, R.; Leatham-Jensen, M.P.; Gibson, T.; Cohen, P.S.; Conway, T. Nutritional basis for colonization resistance by human commensal Escherichia coli strains HS and nissle 1917 against E. coli O157:H7 in the mouse intestine. PLoS One 2013, 8, e53957.

50. Resta-Lenert, S.; Barrett, K.E. Live probiotics protect intestinal epithelial cells from the effects of infection with enteroinvasive Escherichia coli (EIEC). Gut 2003, 52, 988-997.

51. Cario, E.; Gerken, G.; Podolsky, D.K. Toll-like receptor 2 enhances ZO-1-associated intestinal epithelial barrier integrity via protein kinase C. Gastroenterology 2004, 127, 224-238.

52. Petrof, E.O.; Kojima, K.; Ropeleski, M.J.; Tao, Y.; de Simone, C.; Chang, E.B. Probiotics inhibit nuclear factor kappaB and induce heat shock proteins in colonic epithelial cells through proteasome inhibition. Gastroenterology 2004, 127, 1474-1487.

53. Tao, Y.; Drabik, K.A.; Waypa, T.S.; Musch, M.W.; Alverdy, J.C.; Schneewind, O.; Chang, E.B.; Petrof, E.O. Soluble factors from Lactobacillus GG activate MAPKs and induce cytoprotective heat shock proteins in intestinal epithelial cells. Am. J. Physiol. Cell Physiol. 2006, 290, C1018-C1030.

54. Park, H.S.; Cho, S.G.; Kim, C.K.; Hwang, H.S.; Noh, K.T.; Kim, M.S.; Huh, S.H.; Kim, M.J.; Ryoo, K.; Kim, E.K.; et al. Heat shock protein hsp72 is a negative regulator of apoptosis signal-regulating kinase 1. Mol. Cell Biol. 2002, 22, 7721-7730.

55. Liu, T.S.; Musch, M.W.; Sugi, K.; Walsh-Reitz, M.M.; Ropeleski, M.J.; Hendrickson, B.A.; Pothoulakis, C.; Lamont, J.T.; Chang, E.B. Protective role of HSP72 against Clostridium difficile toxin A-induced intestinal epithelial cell dysfunction. Am. J. Physiol. Cell Physiol. 2003, 284, C1073-1082.

56. Gendler, S.J.; Spicer, A.P. Epithelial mucin genes. Annu. Rev. Physiol. 1995, 57, 607-634.

57. Van Tassell, M.L.; Miller, M.J. Lactobacillus adhesion to mucus. Nutrients 2011, 3, 613-636.

58. Mack, D.R.; Michail, S.; Wei, S.; McDougall, L.; Hollingsworth, M.A. Probiotics inhibit enteropathogenic E. coli adherence in vitro by inducing intestinal mucin gene expression. Am. J. Physiol. 1999, 276, G941-G950.

59. Caballero-Franco, C.; Keller, K.; de Simone, C.; Chadee, K. The VSL\#3 probiotic formula induces mucin gene expression and secretion in colonic epithelial cells. Am. J. Physiol. Gastrointest. Liver Physoil. 2007, 292, 315-322.

60. Perez-Vilar, J.; Hill, R.L. The structure and assembly of secreted mucins. J. Biol. Chem. 1999, 274, 31751-31754.

61. Katayama, T.; Fujita, K.; Yamamoto, K. Novel bifidobacterial glycosides action on sugar chains of mucin glycoproteins. J. Biosci. Bioeng. 2005, 99, 457-465.

62. Kiyohara, M.; Nakatomi, T.; Kurihara, S.; Fushinobu, S.; Suzuki, H.; Tanaka, T.; Shoda, S.; Kitaoka, M.; Katayama, T.; Yamamoto, K.; et al. $\alpha$-N-acetylgalactosaminidase from infant-associated bifidobacteria belonging to novel glycoside hydrolase family 129 is implicated in alternative mucin degradation pathway. J. Biol. Chem. 2012, 287, 693-700.

63. Biesbrock, A.R.; Reddy, M.S.; Levine, M.J. Interaction of a salivary mucin-secretory immunoglobulin A complex with mucosal pathogens. Infect. Immun. 1991, 59, 3492-3497.

64. Rautava, S.; Arvilommi, H.; Isolaur, E. Specific probiotics in enhancing maturation of IgA responses in formula-fed infants. Pediatr. Res. 2006, 60, 221-224. 
65. Rodrigues, A.C.; Cara, D.C.; Fretez, S.H.; Cunha, F.Q.; Vieira, E.C.; Nicoli, J.R.; Vieira, L.Q. Saccharomyces boulardii stimulates sIgA production and the phagocytic system of gnotobiotic mice. J. Appl. Microbiol. 2000, 89, 404-414.

66. He, B.; Xu, W.; Santini, P.A.; Polydorides, A.D.; Chiu, A.; Estrella, J.; Shan, M.; Chadburn, A.; Villanacci, V.; Plebani, A.; et al. Intestinal bacteria trigger T cell-independent immunoglobulin A2 class switching by inducing epithelial-cell secretion of the cytokine APRIL. Immunity 2007, 26, 812-826.

67. Shang, L.; Fukata, M.; Thirunarayanan, N.; Martin, A.P.; Arnaboldi, P.; Maussang, D.; Berin, C.; Unkeless, J.C.; Mayer, L.; Abreu, M.T.; et al. Toll-like receptor signaling in small intestinal epithelium promotes B-cell recruitment and IgA production in lamina propria. Gastroenterology 2008, 135, 529-538.

68. Reséndiz-Albor, A.A.; Reina-Garfias, H.; Rojas-Hernández, S.; Jarillo-Luna, A.; Rivera-Aguilar, V.; Miliar-García, A.; Campos-Rodríguez, R. Regionalization of pIgR expression in the mucosa of mouse small intestine. Immunol. Lett. 2010, 128, 59-67.

69. Gillor, O.; Giladi, I.; Riley, M.A. Persistance of colicinogenic Escherichia coli in the mouse gastrointestinal tract. BMC Microbiol. 2009, 9, 165.

70. Tong, Z.; Zhou, L.; Li, J.; Kuang, R.; Lin, Y.; Ni, L. An in vitro investigation of Lactococcus lactis antagonising cariogenic bacterium Streptococcus mutans. Arch. Oral Biol. 2012, 57, 376-382.

71. Corr, S.C.; Li, Y.; Riedel, C.U.; O’Toole, P.W.; Hill, C.; Gahan, C.G. Bacteriocin production as a mechanism for the antiinfective activity of Lactobacillus salivarius UCC118. Proc. Natl. Acad. Sci. USA 2007, 104, 7617-7621.

72. Meijerink, M.; van Hemert, S.; Taverne, N.; Wels, M.; de Vos, P.; Bron, P.A.; Savelkoul, H.F.; van Bilsen, J.; Kleerebezem, M.; Wells, J.M. Identification of genetic loci in Lactobacillus plantarum that modulate the immune response of dendritic cells using comparative genome hybridization. PLoS One 2010, 5, e10632.

73. Casey, P.G.; Gardiner, G.E.; Casey, G.; Bradshaw, B.; Lawlor, P.G.; Lynch, P.B.; Leonard, F.C.; Stanton, C.; Ross, R.P.; Fitzgerald, G.F.; et al. A five-strain probiotic combination reduces pathogen shedding and alleviates disease signs in pigs challenged with Salmonella enterica Serovar Typhimurium. Appl. Envrion. Microb. 2007, 73, 1858-1863.

74. Dabour, N.; Zihler, A.; Kheadr, E.; Lacroix, C.; Fliss, I. In vivo study on the effectiveness of pediocin PA-1 and Pediococcus acidilactici UL5 at inhibiting Listeria monocytogenes. Int. J. Food Microbiol. 2009, 133, 225-233.

75. Rea, M.C.; Dobson, A.; O’Sullivan, O.; Crispie, F.; Fouhy, F.; Cotter, P.D.; Shanahan, F.; Kiely, B.; Hill, C.; Ross, R.P. Effect of broad- and narrow-spectrum antimicrobials on Clostridium difficile and microbial diversity in a model of the distal colon. Proc. Natl. Acad. Sci. USA 2011, 108, 4639-4644.

76. McAuliffe, O.; Ryan, M.P.; Ross, R.P.; Hill, C.; Breeuwer, P.; Abee, T. Lacticin 3147, a broad-spectrum bacteriocin which selectively dissipates the membrane potential. Appl. Environ. Microbiol. 1998, 64, 439-445. 
77. Ganz, T.; Selsted, M.E.; Szklarek, D.; Harwig, S.S.; Daher, K.; Bainton, D.F.; Lehrer, R.I. Defensins. Natural peptide antibiotics of human neutrophils. J. Clin. Invest. 1985, 76, 1427-1435.

78. Selsted, M.E.; Harwig, S.S.; Ganz, T.; Schilling, J.W.; Lehrer, R.I. Primary structures of three human neutrophil defensins. J. Clin. Invest. 1985, 76, 1436-1439.

79. Ayabe, T.; Satchell, D.P.; Pesendorfer, P.; Tanabe, H.; Wilson, C.L.; Hagen, S.J.; Ouellette, A.J. Activation of Paneth cell alpha-defensins in mouse small intestine. J. Biol. Chem. 2002, 277, 5219-5228.

80. Möndel, M.; Schroeder, B.O.; Zimmermann, K.; Huber, H.; Nuding, S.; Beisner, J.; Fellermann, K.; Stange, E.F.; Wehkamp, J. Probiotic E. coli treatment mediates antimicrobial human beta-defensin synthesis and fecal excretion in humans. Mucosal Immunol. 2009, 2, 166-172.

81. Schlee, M.; Wehkamp, J.; Altenhoefer, A.; Oelschlaeger, T.A.; Stange, E.F.; Fellermann, K. Induction of human beta-defensin 2 by the probiotic Escherichia coli Nissle 1917 is mediated through flagellin. Infect. Immun. 2007, 75, 2399-2407.

82. Schlee, M.; Harder, J.; Köten, B.; Stange, E.F.; Wehkamp, J.; Fellermann, K. Probiotic lactobacilli and VSL\#3 induce enterocyte beta-defensin 2. Clin. Exp. Immunol. 2008, 151, 528-535.

83. Hugo, A.A.; de Antoni, G.L.; Pérez, P.F. Lactobacillus delbrueckii subsp lactis (strain CIDCA 133) resists the antimicrobial activity triggered by molecules derived from enterocyte-like Caco-2 cells. Lett. Appl. Microbiol. 2010, 50, 335-340.

84. Yang, D.; Chertov, O.; Bykovskaia, S.N.; Chen, Q.; Buffo, M.J.; Shogan, J.; Anderson, M.; Schröder, J.M.; Wang, J.M.; Howard, O.M.; Oppenheim, J.J. Beta-defensins: Linking innate and adaptive immunity through dendritic and T cell CCR6. Science 1999, 286, 525-528.

85. Ismail, A.S.; Severson, K.M.; Vaishnava, S.; Behrendt, C.L.; Yu, X.; Benjamin, J.L.; Ruhn, K.A.; Hou, B.; DeFranco, A.L.; Yarovinsky, F.; et al. $\gamma \delta$ intraepithelial lymphocytes are essential mediators of host-microbial homeostasis at the intestinal mucosal surface. Proc. Natl. Acad. Sci. USA 2011, 108, 8743-8748.

86. Li, Z.; Zhang, C.; Zhou, Z.; Zhang, J.; Zhang, J.; Tian, Z. Small intestinal CD8+TCR $\gamma \delta+$ intraepithelial lymphocytes (iIELs) are involved in bacterial clearance during Salmonella typhimurium infection. Infect. Immun. 2012, 80, 565-574.

87. Roselli, M.; Finamore, A.; Nuccitelli, S.; Carnevali, P.; Brigidi, P.; Vitali, B.; Nobili, F.; Rami, R.; Garaguso, I.; Mengheri, E. Prevention of TNBS-induced colitis by different Lactobacillus and Bifidobacterium strains is associated with as expansion of $\gamma \delta \mathrm{T}$ and regulatory T cells of intestinal intraepithelial lymphocytes. Inflamm. Bowel Dis. 2009, 15, 1526-1536.

88. Li, Y.; Innocentin, S.; Withers, D.R.; Roberts, N.A.; Gallagher, A.R.; Grigorieva, E.F.; Wilhelm, C.; Veldhoen, M. Exogenous stimuli maintain intraepithelial lymphocytes via Aryl hydrocarbon receptor activation. Cell 2011, 147, 629-640.

89. Schulz, V.J.; Smit, J.J.; Willemsen, K.J.; Fiechter, D.; Hassing, I.; Bleumink, R.; Boon, L.; van den Berg, M.; van Duursen, M.B.M.; Pieters, R.H.H. Activation of the aryl hydrocarbon receptor suppresses sensitization in a mouse peanut allergy model. Toxicol. Sci. 2011, 123, 491-500. 
90. Van Baarlen, P.; Troost, F.J.; van Hemert, S.; van der Meer, C.; de Vos, W.M.; de Groot, P.J.; Hooiveld, G.J.E.J.; Brummer, R.M.; Kleerebezem, M. Differential NF-кB pathways induction by Lactobacillus plantarum in the duodenum of healthy humans correlating with immune tolerance. Proc. Natl. Acad. Sci. USA 2009, 106, 2371-2376.

91. Hershberg, R.M.; Cho, D.H.; Youakim, A.; Bradley, M.B.; Lee, J.S.; Framson, P.E.; Nepom, G.T. Highly polarized HLA class II antigen processing and presentation by human intestinal epithelial cells. J. Clin. Invest. 1998, 102, 792-803.

92. Snoeck, V.; Goddeeris, B.; Cox, E. The role of enterocytes in the intestinal barrier function and antigen uptake. Microbes Infect. 2005, 7, 997-1004.

93. Bloom, S.; Simmons, D.; Jewell, D.P. Adhesion molecules intercellular adhesion mole-1 (ICAM-1), ICAM-3 and B7 are not expressed by epithelium in normal or inflamed colon. Clin. Exp. Immunol. 1995, 101, 157-163.

94. Rimoldi, M.; Chieppa, M.; Salucci, V.; Avogadri, F.; Sonzogni, A.; Sampietro, G.M.; Nespoli, A.; Viale, G.; Allavena, P.; Rescigno, M. Intestinal immune homeostasis is regulated by the crosstalk between epithelial cells and dendritic cells. Nat. Immunol. 2005, 6, 507-514.

95. Taylor, B.C.; Zaph, C.; Troy, A.E.; Du, Y.; Guild, K.J.; Comeau, M.R.; Artis, D. TSLP regulates intestinal immunity and inflammation in mouse models of helminth infection and colits. J. Exp. Med. 2009, 206, 655-667.

96. Niess, J.H.; Brand, S.; Gu, X.; Landsman, L.; Jung, S.; McCormick, B.A.; Vyas, J.M.; Boes, M.; Ploegh, H.L.; Fox, J.G.; et al. CX3CR1-mediated dendritic cell access to the intestinal lumen and bacterial clearance. Science 2005, 307, 254-258.

97. Chieppa, M.; Rescigno, M.; Huang, A.Y.C.; Germain, R.N. Dynamic imaging of dendritic cell extension into the small bowel lumen in response to epithelial cell TLR engagement. J. Exp. Med. 2006, 203, 2841-2852.

98. Rescigno, M.; Urbano, M.; Valzasina, B.; Francolini, M.; Rotta, G.; Bonasio, R.; Granucci, F.; Krasehenbuhl, J.P.; Ricciardi-Castagnoli, P. Dendritic cells express tight junction proteins and penetrate gut epithelial monolayers to sample bacteria. Nat. Immunol. 2001, 2, 361-367.

99. Jang, M.H.; Kweon, M.; Iwatani, K.; Yamamoto, M.; Terahara, K.; Sasakawa, C.; Suzuki, T.; Nochi, T.; Yokota, Y.; Rennert, P.D.; et al. Intestinal villous M cells: An antigen entry site in the mucosal epithelium. Proc. Natl. Acad. Sci. USA 2004, 101, 6110-6115.

100. Neutra, M.R.; Mantis, N.J.; Frey, A.; Giannasca, P.J. The composition and function of M cell apical membranes: Implications for microbial pathogenesis. Semin. Immunol. 1999, 11, 171-181.

101. Abreu, M. Toll-like receptor signalling in the intestinal epithelium: How bacterial recognition shapes intestinal function. Nat. Rev. Immunol. 2010, 10, 131-144.

102. Gewirtz, A.T.; Navas, T.A.; Lyons, S.; Godowski, P.J.; Madara, J.L. Cutting edge: Bacterial flagellin activates basolaterally expressed TLR5 to induce epithelial proinflammatory gene expression. J. Immunol. 2001, 164, 1882-1885.

103. Rhee, S.H.; Im, E.; Riegler, M.; Kokkotou, E.; O’Brien, M.; Pothoulakis, C. Pathophysiological role of Toll-like receptor 5 engagment by bacterial flagellin in colonic inflammation. Proc. Natl. Acad. Sci. USA 2005, 102, 13610-13615.

104. Eckmann, L.; Kagnoff, M.F.; Fierer, J. Epithelial cells secrete the chemokine interleukin-8 in response to bacterial entry. Infect. Immun. 1993, 61, 4569-4574. 
105. Otte, J.M.; Podolsky, D.K. Functional modulation of enterocytes by gram-positive and gram-negative microorganisms. Am. J. Physiol. Gastrointest. Liver Physiol. 2004, 286, G613-G626.

106. Barbier de La Serre, C.; Ellis, C.L.; Lee, J.; Hartman, A.L.; Rutledge, J.C.; Raybould, H.E. Propensity to high-fat diet-induced obesity in rats is associated with changes in the gut microbiota and gut inflammation. Am. J. Physiol. Gastrointest. Liver Physiol. 2010, 299, G440-G448.

107. Koyama, I.; Matsunaga, T.; Harada, T.; Hokari, S.; Komoda, T. Alkaline phosphatases reduce toxicity of lipopolysaccharides in vivo and in vitro through dephosphorylation. Clin. Biochem. 2002, 35, 455-461.

108. Bates, J.M.; Akerlund, J.; Mittge, E.; Guillemin, K. Intestional alkaline phosphatase detoxifies lipopolysaccharide and prevents inflammation in response to the gut microbiota. Cell Host Microbe 2007, 2, 371-382.

109. Lee, J.; Mo, J.H.; Katakura, K.; Alkalay, I.; Rucker, A.N.; Liu, Y.T.; Lee, H.K.; Shen, C.; Cojocaru, G.; Shenouda, S.; et al. Maintenance of colonic homeostasis by distinctive apical TLR9 signalling in intestinal epithelial cells. Nat. Cell Biol. 2006, 8, 1327-1336.

110. Shibolet, O.; Podolsky, D.K. TLRs in the Gut. IV. Negative regulation of Toll-like receptors and intestinal homeostasis: Addition by subtraction. Am. J. Physiol. Gastrointest. Liver Physiol. 2007, 292, G1469-G1473.

111. Rudensky, A.Y. Regulatory T-cells and Foxp3. Immunol. Rev. 2011, 241, 260-268.

112. Josefowicz, S.Z.; Lu, L.F.; Rudensky, A.Y. Regulatory T-cells: Mechanisms of differentiation and function. Annu. Rev. Immunol. 2012, 30, 531-364.

113. Lavasani, S.; Dzhambazov, B.; Nouri, M.; Fak, F.; Buske, S.; Molin, G.; Thorlacius, H.; Alenfall, J.; Jeppsson, B.; Westrom, B. A novel probiotic mixture exerts a therapeutic effect on experimental autoimmune encephalomyelitis mediated by IL-10 producing regulatory T-cells. PLoS One 2010, 5, e9009.

114. Haller, D.; Serrant, P.; Granato, D.; Schiffrin, E.J.; Blum, S. Activation of human NK cells by Staphylocci and Lactobacilli requires cell contact-dependent costimulation by autologous monocytes. Clin. Diagn. Lab. Immunol. 2002, 9, 649-657.

115. Smits, H.H.; Engering, A.; ven der Kleij, D.; de Jong, E.C.; Schipper, K.; van Capel, T.M.; Zaat, B.A.; Yazdanbakhsh, M.; Wierenga, E.A.; van Kooyk, Y.; et al. Selective probiotic bacteria induce IL-10-producing regulatory T-cells in vitro by modulating dendritic cell function through dendritic cell-specific intercellular adhesion molecule 3-grabbing nonintegrin. J. Allergy Clin. Immunol. 2005, 115, 1260-1267.

116. Jeon, S.G.; Kayama, H.; Ueda, Y.; Takahashi, T.; Asahara, T.; Tsuji, H.; Tsuji, N.M.; Kiyono, H.; Ma, J.S.; Kusu, T.; et al. Probiotic Bifidobacterium breve induces IL-10 producing Tr1 cells in the colon. PLoS One 2012, 8, e1002714.

117. Peterson, E.R.; Claesson, H.; Schmidt, E.G.; Jensen, S.S.; Ravn, P.; Olsen, J.; Ouwehand, A.; Kristensen, N. Consumption of probiotics increases the effect of regulatory T-cells in transfer colitis. Inflamm. Bowel Dis. 2012, 18, 1-12. 
118. Re, F.; Strominger, J.L. IL-10 released by concomitant TLR-2 stimulation blocks the induction of a subset of Th1 cytokines that are specifically induced by TLR-4 or TLR-3 in human dendritic cells. J. Immunol. 2004, 173, 7548-7555.

119. Coombes, J.L.; Siddiqui, K.R.; Arancibia-Carcamo, C.V.; Hall, J.; Sun, C.M.; Belkaid, Y.; Powrie, F. A functionally specialised population of mucosal CD103+ DCs induces Foxp3+ regulatory T-cells via a TGF- $\beta$ and retinoic acid-dependent manner. J. Exp. Med. 2007, 204, 1757-1764.

120. Evrard, B.; Coudeyras, S.; Dosgilbert, A.; Charbonnel, N.; Alame, J.; Tridon, A.; Forestier, C. Dose-dependent immunomodulation of human dendritic cells by the probiotic Lactobacillus rhamnosus Lcr35. PLoS One 2011, 6, e18735.

121. Miettinen, M.; Matikainen, S.; Vuopio-Varkila, J.; Pirhonen, J.; Varkila, K.; Kurimoto, M.; Julkunen, I. Lactobacilli and streptococci induce interleukin-12 (IL-12), IL-18 and gamma interferon production in human peripheral blood mononuclear cells. Infect. Immun. 1998, 66, 6058-6062.

122. Pochard, P.; Gossett, P.; Grangette, C.; Andre, C.; Tonnel, A.; Pestel, J.; Mercenier, A. Lactic acid bacteria inhibit Th2 cytokine production by mononuclear cells from allergic patients. Basic Clin. Immunol. 2002, 110, 617-623.

123. Niers, L.E.; Timmerman, H.M.; Rijkers, G.T.; van Bleek, G.M.; van Uden, N.O.; Knol, E.F.; Kapsenberg, M.L.; Kimpen, J.L.; Hoekstra, M.O. Identification of strong interleukin-10 inducing lactic acid bacteria which down-regulate T helper type 2 cytokines. Clin. Exp. Allergy 2005, 35, 1481-1489.

124. Shida, K.; Suzuki, T.; Kiyoshima-Shibata, J.; Shimada, S.I.; Nanno, M. Essential roles of monocytes in stimulating human peripheral blood mononuclear cells with Lactobacillus casei to produce cytokines and augment natural killer cell activity. Clin. Vaccine Immunol. 2006, 13, 997-1003.

125. Takeda, K.; Suzuki, T.; Shimada, S.I.; Shida, K.; Nanno, M.; Okumura, K. Interleukin-12 is involved in the enhancement of human natural killer cell activity by Lactobacillus casei Shirota. Clin. Exp. Immunol. 2006, 146, 109-115.

126. Castellazi, A.M.; Valsecchi, C.; Montagna, L.; Malfa, P.; Ciprandi, G.; Avanzini, M.A.; Marseglia, G.L. In vitro activation of mononuclear cells by two probiotics: Lactobacillus paracasei I 1688, Lactobacillus salivarus I 1794, and their mixture (PSMIX). Immunol. Invest. 2007, 36, 413-421.

127. Medina, M.; Izquierdo, E.; Ennahar, S.; Sanz, Y. Differential immunomodulatory properties of Bifidobacterium longum strains: Relevance to probiotics selection and clinical applications. Clin. Exp. Immunol. 2007, 150, 531-538.

128. Ghadimi, D.; Folster-Holst, R.; de Vrese, M.; Winkler, P.; Heller, K.J.; Schrezenmeir, J. Effects of probiotic bacteria and their genomic DNA on TH1/TH2-cytokine production by peripheral blood mononuclear cells (PBMCs) of healthy and allergic subjects. Immunobiology 2008, 213, 677-692.

129. Dong, H.; Rowland, I.; Tuohy, K.M.; Thomas, L.V.; Yaqoob, P. Selective effects of Lactobacillus casei Shirota on T-cell activation, natural killer cell activity and cytokine production. Clin. Exp. Immunol. 2010, 161, 378-388. 
130. Vissers, Y.M.; Snel, J.; Zuurendonk, P.F.; Smit, B.A.; Wichers, H.J.; Savelkoul, H.F. Differential effects of Lactobacillus acidophilus and Lactobacillus plantarum strains on cytokine induction in human peripheral blood mononuclear cells. FEMS Immunol. Med. Microbiol. 2010, 59, 60-70.

131. O’Mahony, L.; O’Callaghan, L.; McCarthy, J.; Shilling, D.; Scully, P.; Sibartie, S.; Kavanagh, E.; Kirwan, W.O.; Redmond, H.P.; Collins, J.K.; et al. Differential cytokine response from dendritic cells to commensal and pathogenic bacteria in different lymphoid compartments in humans. Am. J. Physiol. Gastrointest. Liver Physiol. 2006, 290, 839-845.

132. Fink, L.N.; Zeuthen, L.H.; Christensen, H.R.; Morandi, B.; Frokiaer, H.; Ferlazzo, G. Distinct gut-derived lactic acid bacteria elicit divergent dendritic cell-mediated NK cell responses. Int. Immunol. 2007, 19, 1319-1327.

133. Mohamadzadeh, M.; Olson, S.; Kalina, W.V.; Ruthel, G.; Demmin, G.L.; Warfield, K.L.; Bavari, S.; Klaenhammer, T.R. Lactobacilli activate human dendritic cells that skew $\mathrm{T}$ cells toward T helper 1 polarisation. Proc. Natl. Acad. Sci. USA 2005, 102, 2880-2885.

134. Ghadimi, D.; Helwig, U.; Schrezenmeir, J.; Heller, K.J.; de Vrese, M. Epigenetic imprinting by commensal probiotics inhibits the IL-23/IL-17 axis in an in vitro model of the intestinal mucosal immune system. J. Leukoc. Biol. 2012, 92, 895-911.

135. Paolillo, R.; Carratelli, C.R.; Sorrentino, S.; Mazzola, N.; Rizzo, A. Immunomodulatory effects of Lactobacillus plantarum on human colon cancer cells. Int. Immunopharmacol. 2009, 9, 1265-1271.

136. Donkor, O.N.; Ravikumar, M.; Proudfoot, O.; Day, S.L.; Apostolopoulos, V.; Paukovics, G.; Vasiljevic, T.; Nutt, S.L.; Gill, H. Cytokine profile and induction of T helper type 17 and regulatory $\mathrm{T}$ cells by human peripheral mononuclear cells after microbial exposure. Clin. Exp. Immunol. 2012, 167, 282-295.

137. Haller, D.; Bode, C.; Hammes, W.P.; Pfeifer, A.M.; Schiffrin, E.J.; Blum, S. Non-pathogenic bacteria elicit a differential cytokine response by intestinal epithelial cell/leucocyte co-cultures. Gut 2000, 47, 79-87.

138. Foey, A.D. Mucosal Macrophages: Phenotypr and Functionality in Homeostasis and Pathology. In Handbook of Macrophages: Life Cycle, Functions and Diseases; Takahashi, R., Kai, H., Eds.; Nova Science Publishers Inc.: New York, NY, USA, 2012; Chapter 4, pp. 121-146.

139. Habil, N.; Al-Murrani, W.; Beal, J.; Foey, A.D. Probiotic bacterial strains differentially modulate macrophage cytokine production in a strain-dependent and cell subset-specific manner. Benef. Microbes 2011, 2, 283-293.

140. Habil, N.; Beal, J.; Foey, A. Lactobacillus casei strain Shirota selectively modulates macrophage subset cytokine production. Int. J. Probiotics Prebiotics 2012, 7, 1-12.

141. Foey, A.D. Butyrate regulation of distinct macrophage subsets: Opposing effects on M1 and M2 macrophages. Int. J. Probiotics Prebiotics 2011, 6, 147-158.

142. Helwig, U.; Lammers, K.M.; Rizzello, F.; Brigidi, P.; Rohleder, V.; Caramelli, E.; Gionchetti, P.; Schrezenmeir, J.; Foelsch, U.R.; Schreiber, S.; et al. Lactobacilli, bifidobacteria and E. coli Nissle induce pro- and anti-inflammatory cytokines in peripheral blood mononuclear cells. World J. Gastroenterol. 2006, 12, 5978-5986. 
143. Perez-Cano, F.J.; Dong, H.; Yaqoob, P. In vitro immunomodulatory activity of Lactobacillus fermentum CECT5716 and Lactobacillus salivarius CECT5713: Two probiotic strains isolated from human breast milk. Immunobiology 2010, 215, 996-1004.

144. Thomas, C.M.; Hong, T.; van Pijkeren, J.P.; Hemarajata, P.; Trinh, D.V.; Hu, W.; Britton, R.A.; Kalkum, M.; Versalovic, J. Histamine derived from probiotic Lactobacillus reuteri suppresses TNF via modulation of PKA and ERK signalling. PLoS One 2012, 7, e31951.

145. Ruiz, P.A.; Hoffmann, M.; Szcesny, S.; Blaut, M.; Haller, D. Innate mechanisms for Bifidobacterium lactis to activate transient pro-inflammatory host responses in intestinal epithelial cells after the colonisation of germ-free rats. Immunology 2005, 115, 441-450.

146. Vinderola, G.; Matar, C.; Perdigon, G. Role of intestinal epitelial cells in immune effects mediated by gram-positive probiotic bactéria: Involvement of toll-like receptors. Clin. Diagn. Lab. Immunol. 2005, 12, 1075-1084.

147. Hart, A.L.; Lammers, K.; Brigidi, P.; Vitali, B.; Rizzello, F.; Gionchetti, P.; Campieri, M.; Kamm, M.A.; Knight, S.C.; Stagg, A.J. Modulation of human dendritic cell phenotype and function by probiotic bacteria. Gut 2004, 53, 1602-1609.

148. Braat, H.; van den Brande, J.; van Tol, E.; Hommes, D.; Peppelenbosch, M.; van Deventer, S. Lactobacillus rhamnosus induces peripheral hyporesponsiveness in stimulated CD4+ Tcells via modulation of dendritic cell function. Am. J. Nutr. 2004, 80, 1618-1625.

149. Latvala, S.; Pietila, T.E.; Veckman, V.; Kekkonen, R.A.; Tynkknen, S.; Korpela, R.; Julkunen, I. Potentially probiotic bacteria induce efficient maturation but differential cytokine production in human monocyte-derived dendritic cells. World J. Gastroenterol. 2008, 14, 5570-5583.

150. Koniecza, P.; Groeger, D.; Ziegler, M.; Frei, R.; Ferstl, R.; Shanahan, F.; Quigley, E.M.; Kiely, B.; Akdis, C.A.; O’Mahony, L. Bifidobacterium infantis 35624 administration induces Foxp3 T regulatory cells in human peripheral blood: Potential role for myeloid and plasmacytoid dendritic cells. Gut 2012, 61, 354-366.

151. Strober, W.; Zhang, F.; Kitani, A.; Fuss, I.; Fichtner-Feigl, S. Proinflammatory cytokines underlying the inflammation of Crohn's disease. Curr. Opin. Gastroenterol. 2010, 26, 310-307.

152. Chen, Z.; O'Shea, J.J. Regulation of IL-17 production in human lymphocytes. Cytokine 2008, 41, 71-78.

153. Cooke, A. Th17 cells in inflammatory conditions. Rev. Diabet. Stud. 2006, 3, 72-75.

154. Dicksved, J.; Halfvarson, J.; Rosenquist, M.; Jarnernot, G.; Tysk, C.; Apajalahti, J.; Engstrand, L.; Jansson, J.K. Molecular analysis of the gut microbiota of identical twins with Crohn's disease. ISME 2008, 2, 716-727.

155. Erickson, A.R.; Cantarel, B.L.; Lamendella, R.; Darzi, Y.; Mongodin, E.F.; Pan, C.; Shah, M.; Halfvarson, J.; Tysk, C.; Henrissat, B.; et al. Integrated metagenomics/metaproteomics reveals human host-micrbiota signatures of Crohns' disease. PLoS One 2012, 7, e49138.

156. Maeda, S.; Hsu, L.C.; Liu, H.; Bankston, L.A.; Limura, M.; Kagnoff, M.F.; Eckmann, L.; Karin, M. Nod 2 mutation in Crohn's disease potentiates NF- $\kappa$ B activity and IL-1 $\beta$ processing. Science 2006, 307, 734-738.

157. Hong, J.; Leung, E.; Fraser, A.G.; Merriman, T.R.; Vishnu, P.; Krissansen, G.W. TLR2, TLR4 and TLR9 polymorphisms and Crohn's disease in a New Zealand Caucasian cohort. J. Gastroenterol. Hepatol. 2006, 22, 1760-1766. 
158. Hugot, J. CARD15/NOD2 mutations in Crohn's disease. Ann. N. Y. Acad. Sci. 2006, 1072, 9-18.

159. Netea, M.G.; Kullberg, B.J.; de Jong, D.J.; Franke, B.; Sprong, T.; Naber, T.H.J.; Drenth, J.P.H.; van der Meer, J.W. NOD2 mediates anti-inflammatory signals induced by TLR2 ligands: Implications for Crohn's disease. Eur. J. Immunol. 2004, 34, 2052-2059.

160. Sokol, H.; Pigneur, B.; Watterlot, L.; Lakhdari, O.; Bermudez-Humaran, L.G.; Gratadoux, J.J.; Blugeon, S.; Bridonneau, C.; Furet, J.P.; Corthier, G.; et al. Feacalibacterium prausnitzii is an anti-inflammatory commensal bacterium identified by gut microbiota analysis of Crohn disease patients. Proc. Natl. Acad. Sci. USA 2008, 105, 16731-16736.

161. Jia, W.; Whitehead, R.N.; Griffiths, L.; Dawson, C.; Waring, R.H.; Ramsden, D.B.; Hunter, J.O.; Cole, J.A. Is the abundance of Faecalibacterium prausnitzii relevant to Crohn's disease? FEMS Microbiol. Lett. 2010, 310, 138-144.

162. Van Immerseel, F.; Ducatelle, R.; de Vos, M.; Boon, N.; van de Wiele, T.; Verbeke, K.; Rutgeerts, P.; Sas, B.; Louis, P.; Flint, H.J. Butyric acid-producing anaerobic bacteria as a novel probiotic treatment approach for inflammatory bowel disease. J. Med. Microbiol. 2010, 59, 141-143.

163. Duncan, S.H.; Hold, G.L.; Harmsen, H.J.M.; Stewart, C.S.; Flint, H.J. Growth requirements and fermentation products of Fusobacterium prausnitzii, and a proposal to reclassify it as Faecalibacterium prausnitzii gen. nov., comb. nov. Int. J. Syst. Evol. Microbiol. 2002, 52, 2141-2146.

164. Pryde, S.E.; Duncan, S.H.; Hold, G.L.; Stewart, C.S.; Flint, H.J. The microbiology of butyrate formation in the human colon. FEMS Micrbiol. Lett. 2002, 217, 133-139.

165. Tuohy, K.M.; Rouzaud, G.C.M.; Bruck, W.M.; Gibson, G.R. Modulation of the human gut microflora towards improved health using prebiotics — assessment of efficacy. Curr. Pharm. Des. 2005, 11, 75-90.

166. Ramirez-Farias, C.; Slezak, K.; Fuller, Z.; Duncan, A.; Holtrop, G.; Louis, P. Effect of inulin on the human gut microbiota: Stimulation of Bifidobacterium adolescentis and Faecalibacterium prausnitzii. Br. J. Nutr. 2009, 101, 541-550.

167. Benjamin, J.L.; Hedin, C.R.H.; Koutsoumpas, A.; Ng, S.C.; McCarthy, N.E.; Hart, A.L.; Kamm, M.A.; Sanderson, J.D.; Knight, S.C.; Forbes, A.; et al. Randomised, double-blind, placebo-controlled trail of fructo-oligosaccharides in active Crohn's disease. Gut 2011, 60, 923-929.

168. Schultz, M.; Veltkamp, C.; Dieleman, L.A.; Grenther, W.B.; Wyrick, P.B.; Tonkonogy, S.L.; Sartor, R.B. Lactobacillus plantarum $299 \mathrm{v}$ in the treatment and prevention of spontaneous colitis in interleukin-10-deficient mice. Inflamm. Bowel Dis. 2002, 8, 71-80.

169. Dieleman, L.A.; Goerres, M.S.; Arends, A.; Sprengers, D.; Torrice, C.; Hoentjen, F.; Grenther, W.B.; Sartor, R.B. Lactobacillus GG prevents recurrence of colitis in HLA-B27 transgenic rats after antibiotic treatment. Gut 2003, 52, 370-376.

170. Furrie, E.; Macfarlane, S.; Kennedy, A.; Cummings, J.H.; Walsh, S.V.; O’Neil, D.A.; Macfarlane, G.T. Synbiotic therapy (Bifidobacterium longum/Synergy1) initiates resolution of inflammation in patients with active ulcerative colitis: A randomised controlled pilot trial. Gut 2005, 54, 242-249. 
171. Fujimori, S.; Gudis, K.; Mitsui, K.; Seo, T.; Yonezawa, M.; Tanaka, S.; Tatsuguchi, A.; Sakamoto, C. A randomized controlled trial on the efficacy of synbiotic versus probiotic and prebiotic treatment to improve the quality of life in patients with ulcerative colitis. Nutrition 2009, 25, 520-525.

172. Mennigen, R.; Nolte, K.; Rijcken, E.; Utech, M.; Loeffler, B.; Senninger, N.; Bruewer, M. Probiotic mixture VSL\#3 protects the epithelial barrier by maintaining tight junction protein expression and preventing apoptosis in a murine model of colitis. Am. J. Physiol. Gastrointest. Liver Physiol. 2009, 296, 1140-1149.

173. Miele, E.; Pascarella, F.; Giannetti, E.; Quaglietta, L.; Baldassano, R.N.; Staiano, A. Effect of a probiotic preparation (VSL\#3) on induction and maintenance of remission in children with ulcerative colitis. Am. J. Gastroenterol. 2009, 104, 437-443.

174. Uronis, J.M.; Arthur, J.C.; Keku, T.; Fodor, A.; Carroll, I.M.; Cruz, M.L.; Appleyard, C.B.; Jobin, C. Gut microbial diversity is reduced by the probiotic VSL\#3 and correlates with decreased TNBS-induced colitis. Inflamm. Bowel Dis. 2011, 17, 289-297.

175. Rowland, I.R.; Rumney, C.J.; Coutts, J.T.; Lievense, L.C. Effect of Bifidobacterium longum and inulin on gut bacterial metabolism and carcinogen-induced aberrant crypt foci in rats. Carcinogenesis 1998, 19, 281-285.

176. Femia, A.P.; Luceri, C.; Dolara, P.; Giannini, A.; Biggeri, A.; Salvadori, M.; Clune, Y.; Collins, K.J.; Paglierani, M.; Caderni, G. Antitumorigenic activity of the prebiotic inulin enriched with oligofructose in combination with the prebiotics Lactobacillus rhamnosus and Bifidobacterium lactis in azoxymethane-induced colon carcinogenesis in rats. Carcinogenesis 2002, 23, 1953-1960.

177. Moreno de LeBlanc, A.; Matar, C.; Perdigon, G. The application of probiotics in cancer. Br. J. Nutr. 2007, 98, 105-110.

178. Rafter, J.; Bennett, M.; Caderni, G.; Clune, Y.; Hughes, R.; Karlsson, P.C.; Klinder, A.; O’Riordan, M.; O’Sullivan, G.C.; Pool-Zobel, B.; et al. Dietary synbiotics reduce cancer risk factors in polypectomised and colon cancer patients. Am. J. Clin. Nutr. 2007, 85, 488-496.

179. Bassaganya-Riera, J.; Viladomiu, M.; Pedragosa, M.; de Simone, C.; Carbo, A.; Shaykhutdinov, R.; Jobin, C.; Arthur, J.C.; Corl, B.A.; Vogel, H.; et al. Probiotic bacteria produce conjugated linoleic acid locally in the gut that targets macrophage PPAR-gamma to suppress colitis. PLoS One 2012, 7, e31238.

180. Chen, C.C.; Lin, W.C.; Kong, M.S.; Shi, H.N.; Walker, W.A.; Lin, C.Y.; Huang, C.T.; Lin, Y.C.; Jung, S.M.; Lin, T.Y. Oral inoculation of probiotics Lactobacillus acidophilus NCFM suppresses tumour growth both in segmental orthotopic colon cancer and extra-intestinal tissue. Br. J. Nutr. 2012, 107, 1623-1634.

181. Repa, A.; Grangette, C.; Daniel, C.; Hochreiter, R.; Hoffmann-Sommergruber, K.; Thlhamer, J.; Kraft, D.; Breiteneder, H.; Mercenier, A.; Wiedermann, U. Mucosal co-application of lactic acid bacteria and allergen induces counter-regulatory immune responses in a murine model of birch pollen allergy. Vaccine 2003, 22, 87-95.

182. Van de Pol, M.A.; Lutter, R.; Smids, B.S.; Weersink, E.J.M.; van der Zee, J.S. Synbiotics reduce allergen-induced T-helper 2 response and improve peak expiratory flow in allergic asthmatics. Allergy 2010, 66, 39-47. 
183. Van der Aa, L.B.; Lutter, R.; Heymans, H.S.; Smids, B.S.; Dekker, T.; van Aalderen, W.M.; Sillevis Smitt, J.H.; Knippels, L.M.J.; Garssen, J.; Nauta, A.J.; et al. No detectable beneficial systemic immunomodulatory effects of a specific synbiotic mixture in infants with atopic dermatitis. Clin. Exp. Allergy 2012, 42, 531-539.

184. Van der Aa, L.B.; Heymans, H.S.; van Aalderen, W.M.; Sillevis Smitt, J.H.; Knol, J.; Ben Amor, K.; Goossens, D.A.; Sprikkelman, A.B.; Synbad Study Group. Effect of a new synbiotic mixture on atopic dermatitis in infants: A randomised-controlled trial. Clin. Exp. Allergy 2010, 40, 795-804.

185. D’Arienzo, R.; Maurano, F.; Luongo, D.; Mazzarella, G.; Stefanile, R.; Troncone, R.; Auricchio, S.; Ricca, E.; David, C.; Rossi, M. Adjuvant effect of Lactobacillus casei in a mouse model of gluten sensitivity. Immunol. Lett. 2008, 119, 78-83.

186. Lindfors, K.; Blomqvist, T.; Juuti-Uusitalo, K.; Stenman, S.; Venalainen, J.; Maki, M.; Kaukinen, K. Live probiotic Bifidobacterium lactis bacteria inhibit the toxic effects induced by wheat gliadin in epithelial cell culture. Clin. Exp. Immunol. 2008, 152, 552-558.

187. De Palma, G.; Cinova, J.; Stepankova, R.; Tuckova, L.; Sanz, Y. Pivotal advance: Bifidobacteria and Gram-negative bacteria differentially influence immune responses in the proinflammatory milieu of celiac disease. J. Leukoc. Biol. 2010, 87, 765-778.

188. D’Arienzo, R.; Maurano, F.; Lavermicocca, P.; Ricca, E.; Rossi, M. Modulation of the immune response by probiotic strains in a mouse model of gluten sensitivity. Cytokine 2009, 48, 254-259.

189. Kullberg, M.C.; Jankovic, D.; Feng, C.G.; Hue, S.; Gorelick, P.L.; McKenzie, B.S.; Cua, D.J.; Powrie, F.; Cheever, A.W.; Maloy.; et al. IL-23 plays a key role in Helicobacter hepaticus-induced T cell-dependent colitis. J. Exp. Med. 2006, 203, 2485-2494.

190. Brand, S. Crohn's disease: Th1, Th17 or both? The change of a paradigm: New immunological and genetic insights implicate Th17 cells in the pathogenesis of Crohn's disease. Gut 2009, 58, 1152-1167.

191. Fujimori, S.; Tatsuguchi, A.; Gudis, K.; Kishida, T.; Mitsui, K.; Ehara, A.; Kobayashi, T.; Sekita, Y.; Seo, T.; Sakamoto, C. High dose probiotic and prebiotic cotherapy for the remission induction of active Crohn's disease. J. Gastroenterol. Hepatol. 2006, 22, 1199-1204.

192. Popivanova, B.K.; Kitamura, K.; Wu, Y.; Kondo, T.; Kagaya, T.; Kaneko, S.; Oshima, M.; Fuji, C.; Mukaida, N. Blocking TNF- $\alpha$ in mice reduces colorectal carcinogenesis associated with chronic colitis. J. Clin. Invest. 2008, 118, 560-570.

193. Gophna, U.; Sommerfeld, K.; Gophna, S.; Doolittle, W.F.; Veldhuyzen van Zanten, S.J. Differences between tissue-associated intestinal microfloras of patients with Crohn's disease and Ulcerative colitis. J. Clin. Microbiol. 2006, 44, 4136-4141.

194. Sood, A.; Midha, V.; Makharia, G.K.; Ahuja, V.; Singal, D.; Goswami, P.; Tandon, R.K. The probiotic preparation, VSL\#3, induces remission in patients with mild-to-moderately active ulcerative colitis. Clin. Gastroenterol. Heptol. 2009, 7, 1202-1209.

195. Henriksen, M.; Jahnsen, J.; Lygren, I.; Stray, N.; Sauar, J.; Vatn, M.H.; Moum, B.; IBSEN Study Group. C-reactive protein: A predictive factor and marker of inflammation in inflammatory bowel disease. Results from a prospective population-based study. Gut 2008, 57, 1518-1523. 
196. Rizello, V.; Bonaccorsi, I.; Dongarra, M.L.; Fink, L.N.; Ferlazzo, G. Role of natural killer and dendritic cell crosstalk in immunomodulation by commensal bacteria probiotics. J. Biomed. Biotechnol. 2011, 2011, 1-10.

197. Szaradkiewicz, A.; Marciniak, R.; Chudzicka-Strugala, I.; Wasilewska, A.; Drews, M.; Majewski, P.; Karpinski, T.; Zwozdziak, B. Proinflammatory cytokines and IL-10 in inflammatory bowel disease and colorectal cancer patients. Arch. Immunol. Ther. Exp. 2009, 57, 291-294.

198. Kane, K.F.; Langman, M.J.; Williams, G.R. Antiproliferative responses of two human colon cancer cell lines to Vitamin D3 are differentially modified by 9-cis-retionic acid. Cancer Res. 1996, 56, 623-632.

199. Muscat, J.; Wynder, E.L. The consumption of well-done red meat and the risk of colorectal cancer. Am. J. Public Health 1994, 84, 856-858.

200. Le Marchand, L.; Hankin, J.H.; Wilkens, L.R.; Pierce, L.M.; Franke, A.; Kolonel, L.N.; Seifried, A.; Custer, L.J.; Chang, W.; Lum-Jones, A.; et al. Combined effects of well-done red meat, smoking and rapid N-acetyltransferase 2 and CYP1A2 phenotypes in increasing colorectal cancer risk. Cancer Epidemiol. Biomarkers Prev. 2001, 10, 1259-1266.

201. Herbst, T.; Sichelstiel, A.; Schär, C.; Yadava, K.; Bürki, K.; Cahenzli, J.; McCoy, K.; Marsland, B.J.; Harris, N.L. Dysregulation of allergic airway inflammation in the absence of microbial colonization. Am. J. Respir. Crit. Care Med. 2011 184, 198-205.

202. Abrahamsson, T.R.; Jakobsson, H.E.; Andersson, A.F.; Björkstén, B.; Engstrand, L.; Jenmalm, M.C. Low diversity of the gut microbiota in infants with atopic eczema. J. Allery Clin. Immun. 2012, 129, 434-440.

203. Nylund, L.; Satokari, R.; Nikkilä, J.; Rajilić-Stojanović, M.; Kalliomäki, M.; Isolauri, E.; Salminen, S.; de Vos, W.M. Microarray analysis reveals marked intestinal microbiota aberrancy in infants having eczema compared to healthy children in at-risk for atopic disease. BMC Microbiol. 2013, 13, 12.

204. Lee, H.; Kim, H.; Lee, E.; Jang, M.; Kim, S.; Park, J.; Seoh, J.; Jung, Y. Characterisation of CCR9 expression and thymus-expressed chemokine responsiveness of the murine thymus, spleen and mesenteric lymph nodes. Immunobiology 2012, 217, 402-411.

205. Kalliomäki, M.; Salminen, S.; Arvilommi, H.; Kero, P.; Koskinen, P.; Isolauri, E. Probiotics in primary prevention of atopic disease: A randomised placebo-controlled trial. Lancet 2001, 357, 1076-1079.

206. Böttcher, M.F.; Nordin, E.K.; Sandin, A.; Midtvedt, T.; Björkstén, B. Microflora-associated characteristics in faeces from allergic and nonallergic infants. Clin. Exp. Allergy 2000, 30, 1590-1596.

207. Wakabayashi, H.; Nariai, C.; Takemura, G.; Nakao, W.; Fujiwara, D. Dietary supplementation with lactic acid bacteria attenuates the development of atopic-dermatitis-like skin lesions in NC/Nga mice in a strain-dependent manner. Int. Arch. Allergy Immunol. 2008, 145, 141-151.

208. Tanaka, A.; Jung, K.; Benyacoub, J.; Prioult, G.; Okamoto, N.; Ohmori, K.; Blum, S.; Mercenier, A.; Mastuda, H. Oral supplementation with Lactobacillus rhamnosus CGMCC 1.3724 prevents development of atopic dermatitis in NC/NgaTnd mice possibly by modulating local production of IFN-gamma. Exp. Dermatol. 2009, 18, 1022-1027. 
209. Brouwer, M.L.; Wolt-Plompen, S.A.; Dubois, A.E.; van der Heide, S.; Jansen, D.F.; Hoijer, M.A.; Kauffman, H.F.; Duiverman, E.J. No effects of probiotics on atopic dermatitis in infancy: A randomized placebo-controlled trial. Clin. Exp. Allergy 2006, 36, 899-906.

210. Tanaka, A.; Fukushima, Y.; Bevacoub, J.; Blum, S.; Matsuda, H. Prophylactic effect of oral administration of Lactobacillus johnsonii NCC533 (La1) during the weaning period on atopic dermatitis in NC/NgaTnd mice. Eur. J. Dermatol. 2008, 18, 136-140.

211. Inoue, R.; Nishio, A.; Fukushima, Y.; Ushida, K. Oral treatment with probiotic Lactobacillus johnsonii NCC533 (La1) for a specific part of the weaning period prevents the development of atopic dermatitis induced after maturation in model mice, NC/Nga. Br. J. Dermatol. 2007, 156, 499-509.

212. Wickens, K.; Black, P.; Stanley, T.V.; Mitchell, E.; Fitzharris, P.; Tannock, G.W.; Purdie, G.; Crane, J.; Probiotic Study Group. A differential effect of 2 probiotics in the prevention of eczema and atopy: A double-blind, randomized, placebo controlled trial. J. Allergy Clin. Immunol. 2008, 122, 788-794.

213. Wickens, K.; Black, P.; Stanley, T.V.; Mitchell, E.; Barthow, C.; Fitzharris, P.; Purdie, G.; Crane, J. A protective effect of Lactobacillus rhamnosus HN001 against eczema in the first 2 years of life persists to age 4 years. Clin. Exp. Allergy 2012, 42, 1071-1079.

214. Shah, M.M.; Saio, M.; Yamashita, H.; Tanaka, H.; Takami, T.; Ezaki, T.; Inagaki, N. Lactobacillus acidophilus strain L-92 induces CD4+ CD25+ Foxp3+ regulatory T cells and suppresses allergic contact dermatitis. Biol. Pharm. Bull. 2012, 35, 612-616.

215. Karimi, K.; Inman, M.D.; Bienenstock, J.; Forsythe, P. Lactobacillus reuteri-induced regulatory T cells protect against an allergic airway response in mice. Am. J. Respir. Crit. Care Med. 2009, 197, 186-193.

216. Kwon, H.; Lee, C.; So, J.; Chae, C.; Hwang, J.; Sahoo, A.; Nam, J.; Rhee, J.; Hwang, K.; Im, S. Generation of regulatory dendritic cells and $\mathrm{CD} 4^{+}$Foxp $^{+}$T-cells by probiotics administration suppresses immune disorders. Proc. Natl. Acad. Sci. USA 2010, 107, 2159-2164.

217. Shida, K.; Takahashi, E.; Iwadate, E.; Takamizawa, K.; Yasui, H.; Sato, T.; Habu, S.; Hachimura, S.; Kaminogawa, S. Lactobacillus casei strain Shirota suppresses serum immunoglobulin E and immunoglobulin G1 responses and systemic anaphylaxis in a food allergy model. Clin. Exp. Allergy 2002, 32, 563-570.

218. Takahashi, N.; Kitazawa, H.; Iwabuchi, N.; Xiao, J.Z.; Miyaji, K.; Iwatsuki, K.; Saito, T. Immunostimulatory oligodeoxynucleotide from Bifidobacterium longum suppresses Th2 immune responses in a murine model. Clin. Exp. Immunol. 2006, 145, 130-138.

219. Schiffer, C.; Lalanne, A.I.; Cassard, L.; Mancardi, D.A.; Malbec, O.; Bruhns, P.; Dif, F.; Daeron, M. A strain of Lactobacillus casei inhibits the effector phase of immune inflammation. J. Immunol. 2011, 187, 1-10.

220. Dev, S.; Mizuguchi, H.; Das, A.K.; Matsushita, C.; Maeyama, K.; Umehara, H.; Ohtoshi, T.; Kojima, J.; Nishida, K.; Takahashi, K.; et al. Suppression of histamine signalling by probiotic Lac-B: A possible mechanism of its anti-allergic effect. J. Pharmacol. Sci. 2008, 107, 159-166.

221. Van Heel, D.A.; West, J. Recent advances in coeliac disease. Gut 2006, 55, 1037-1046. 
222. Jabri, B.; Patey-Mariaud De Serre, N.; Cellier, C.; Evans, K.; Gache, C.; Carvalho, C.; Mougenot, J.F.; Allez, M.; Jian, R.; Desreumaux, P.; et al. Selectivr expanision of intraepithelial lymphocytes expressing the HLA-E-specific natural killer receptor CD94 in celiac disease. Gastroenterology 2000, 118, 867-879.

223. Maiuri, L.; Ciacci, C.; Vacca, L.; Ricciardelli, I.; Auricchio, S.; Quaratino, S.; Londei, M. IL-15 drives the specific migration of CD94+ and TCR- $\gamma \delta+$ intraepithelial lymphocytes in organ cultures of treated celiac patients IL-15 and Intraepithelial Migration of CD3 $\gamma \delta$ and CD94. Am. J. Gastroenterol. 2001, 96, 150-156.

224. Meresse, B.; Chen, Z.; Ciszewski, C.; Tretiakova, M.; Bhagat, G.; Krausz, T.N.; Raulet, D.H.; Lanier, L.L.; Groh, V.; Spies, T.; et al. Coordinated induction of IL15 of a TCR-independent NKG2D signaling pathway converts CTL into lymphokine-activated killer cells in celiac disease. Immunity 2004, 21, 357-366.

225. Groh, V.; Steinle, A.; Bauer, S.; Spies, T. Recognition of stress-induced MHC molecules by intestinal epithelial $\gamma \delta$ T cells. Science 1998, 279, 1737-1740.

226. Bauer, S.; Groh, V.; Wu, J.; Steinle, A.; Phillips, J.H.; Lanier, L.L.; Spies, T. Activation of NK cells and T cells by NKG2D, a receptor for stress-inducible MICA. Science 1999, 285, 727-729.

227. Hüe, S.; Mention, J.J.; Monteiro, R.C.; Zhang, S.; Cellier, C.; Schmitz, J.; Verkarre, V.; Fodil, N.; Bahram, S.; Cerf-Bensussan, N.; et al. A direct role for NKG2D/MICA interaction in villous atrophy during celiac disease. Immunity 2004, 21, 367-377.

228. Salvati, V.M.; MacDonald, T.T.; Bajaj-Elliott, M.; Borrelli, M.; Staiano, A.; Auricchio, S.; Troncone, R.; Monteleone, G. Interleukin 18 and associated markers of T helper cell type 1 activity in coeliac disease. Gut 2002, 50, 186-190.

229. Matysiak-B, T.; Moura, I.C.; Arcos-Fajardo, M.; Lebreton, C.; Menard, S.; Candalh, C.; Ben-Khalifa, K.; Dugave, C.; Tamouza, H.; van Niel, G.; et al. Sectretory IgA mediates retrotranscytosis of intact gliadin peptides via the transferrin receptor in celiac disease. J. Exp. Med. 2007, 205, 143-154.

230. Dieterich, W.; Ehnis, T.; Bauer, M.; Donner, P.; Volta, U.; Riecken, E.O.; Schuppan, D. Identification of tissue transglutaminase as the autoantigen of celiac disease. Nat. Med. 1997, 3, 797-801.

231. Dahldom, I.; Korponay-Szabo, I.R.; Kovacs, J.B.; Szalai, Z.; Maki, M.; Hansson, T. Prediction of clinical and mucosal severity of coeliac disease and dermatitis herpetiformis by quantification of IgA/IgG serum antibodies to tissue transglutaminase. J. Pediatr. Gastroenterol. Nutr. 2010, 50, 140-146.

232. Sanz, Y.; Sanchez, E.; Marzotto, M.; Calabuig, M.; Torriani, S.; Dellaglio, F. Differences in faecal bacterial communities in coeliac and healthy children as detected by PCR and denaturing gradient gel electrophoresis. FEMS Immunol. Med. Microbiol. 2007, 51, 562-568.

233. Collado, M.; Donat, E.; Ribes-Koninckx, C.; Calabuig, M.; Sanz, Y. Imbalances in faecal and duodenal Bifidobacterium species composition in active and non-active coeliac disease. BMC Microbiol. 2008, 8, 1-9.

234. Silano, M.; Agostoni, C.; Guandalini, S. Effect of the timing of gluten introduction on the development of celiac disease. World J. Gastroenterol. 2010, 16, 1939-1942. 
235. D’Arienzo, R.; Stefanile, R.; Maurano, F.; Mazzarella, G.; Ricca, E.; Troncone, R.; Auricchio, S.; Rossi, M. Immunomodulatory effects of Lactobacillus casei administration in a mouse model of gliadin-sensitive enteropathy. Basic Immunol. 2011, 74, 335-341.

236. Krupa-Kozak, U.; Altamirano-Fortoul, R.; Wronkowska, M.; Rosell, C.M. Breadmaking performance and technological characteristic of gluten-free bread with inulin supplemented with calcium salts. Eur. Food Res. Technol. 2012, 235, 545-554.

237. Czesnikiewicz-Guzik, M.; Lee, W.-W.; Cui, D.; Hiruma, Y.; Lamar, D.L.; Yang, Z.-Z.; Ouslander, J.G.; Weyand, C.M.; Goronzy, J.J. T cell subset-specific susceptibility to aging. Clin. Immunol. 2008, 127, 107-118.

238. Zhang, Y.; Wallace, D.L.; de Lara, C.M.; Ghattas, H.; Asquith, B.; Worth, A.; Griffin, G.E.; Taylor, G.P.; Tough, D.F.; Beverley, P.C.; et al. In vivo kinetics of human natural killer cells: The effects of ageing and acute and chronic viral infection. Immunology 2007, 121, 258-265.

239. Dong, H.; Rowland, I.; Thomas, L.V.; Yaqoob, P. Immunomodulatory effects of a probiotic drink containing Lactobacillus casei Shirota in healthy older volunteers. Eur. J. Nutr. 2013, doi:10.1007/s00394-012-0487-1.

240. Kim, H.G.; Lee, S.Y.; Kim, N.R.; Ko, M.Y.; Lee, J.M.; Yi, T.H.; Chung, S.K.; Chung, D.K. Inhibitory effects of Lactobacillus plantarum Lipoteichoic acid (LTA) on Staphylococcus aureus LTA-induced tumour necrosis factor-alpha production. J. Microbiol. Biotechnol. 2008, 18, 1191-1196.

241. Kim, H.G.; Lee, S.Y.; Kim, N.R.; Lee, H.Y.; Ko, M.Y.; Jung, B.J.; Kim, C.M.; Lee, J.M.; Park, J.H.; Han, S.H.; Chung, D.K. Lactobacillus plantarum lipoteichoic acid down regulated Shigella flexneri peptidoglycan-induced inflammation. Mol. Immunol. 2011, 48, 382-291.

242. Kleerebezem, M.; Hols, P.; Bernard, E.; Rolain, T.; Zhou, M.; Siezen, R.J.; Bron, P.A. The extracellular biology of the lactobacilli. FEMS Microbiol. Rev. 2010, 34, 199-230.

243. Preidis, G.A.; Versalovic, J. Targeting the human microbiome with antibiotics, probiotics and prebiotics: Gastroenterology enters the metagenomics era. Gastroenterology 2009, 136, 2015-2031.

244. Yatsunenko, T.; Rey, F.E.; Manary, M.J.; Trehan, I.; Dominguez-Bello, M.G.; Contreras, M.; Magris, M.; Hidalgo, G.; Baldassano, R.N.; Anokhin, A.P.; et al. Human gut microbiome viewed across age and geography. Nature 2012, 9, 222-227.

245. Anderson, J.L.; Edney, R.J.; Whelan, K. Systematic review: Faecal microbiota transplantation in the management of inflammatory bowel disease. Aliment. Pharmacol. Ther. 2012, 36, 503-516.

(C) 2013 by the authors; licensee MDPI, Basel, Switzerland. This article is an open access article distributed under the terms and conditions of the Creative Commons Attribution license (http://creativecommons.org/licenses/by/3.0/). 